\title{
A Systematic Review and Meta-analysis of Psychosocial Interventions to Reduce Drug and Sexual Blood Borne Virus Risk Behaviours Among People Who Inject Drugs
}

\author{
Gail Gilchrist $^{1,2} \cdot$ Davina Swan $^{1} \cdot$ Kideshini Widyaratna $^{1} \cdot$ Julia Elena Marquez-Arrico $^{3} \cdot$ \\ Elizabeth Hughes $^{4} \cdot$ Noreen Dadirai Mdege $^{5} \cdot$ Marrissa Martyn-St James ${ }^{6}$. \\ Judit Tirado-Munoz ${ }^{7}$
}

Published online: 1 April 2017

(c) The Author(s) 2017. This article is published with open access at Springerlink.com

\begin{abstract}
Opiate substitution treatment and needle exchanges have reduced blood borne virus (BBV) transmission among people who inject drugs (PWID). Psychosocial interventions could further prevent BBV. A systematic review and meta-analysis examined whether psychosocial interventions (e.g. CBT, skills training) compared to control interventions reduced BBV risk behaviours among PWID. 32 and 24 randomized control trials (2000May 2015 in MEDLINE, PsycINFO, CINAHL, Cochrane Collaboration and Clinical trials, with an update in MEDLINE to December 2016) were included in the review and
\end{abstract}

Electronic supplementary material The online version of this article (doi:10.1007/s10461-017-1755-0) contains supplementary material, which is available to authorized users.

Gail Gilchrist

gail.gilchrist@kcl.ac.uk

1 National Addiction Centre, Institute of Psychiatry, Psychology and Neuroscience, King's College London, 4 Windsor Walk, London SE5 8BB, UK

2 Department of General Practice, University of Melbourne, Parkville, VIC 3010, Australia

3 Department of Psychiatry and Clinical Psychobiology, School of PsychologyUniversity of Barcelona, 08036 Barcelona, Spain

4 University of Huddersfield, Huddersfield HD1 3DH, UK

5 Mental Health and Addiction Research Group, Department of Health Sciences, University of York, York YO24 2YD, UK

6 School for Health and Related Research, University of Sheffield, Regent Court, 30 Regent Street, Sheffield S1 4DA, UK

7 Addiction Research Group, IMIM-Institut Hospital del Mar d'Investigacions Mèdiques, Institute of Neuropsychiatry and Addictions, Parc de Salut Mar de Barcelona, 08003 Barcelona, Spain meta-analysis respectively. Psychosocial interventions appear to reduce: sharing of needles/syringes compared to education/information (SMD $-0.52 ; 95 \% \mathrm{CI}-1.02$ to $\left.-0.03 ; \mathrm{I}^{2}=10 \% ; \mathrm{p}=0.04\right)$ or $\mathrm{HIV}$ testing/counselling ( $\mathrm{SMD}-0.24 ; 95 \% \mathrm{CI}-0.44$ to $-0.03 ; \mathrm{I}^{2}=0 \% ; \mathrm{p}=0.02$ ); sharing of other injecting paraphernalia (SMD $-0.24 ; 95 \%$ $\mathrm{CI}-0.42$ to $\left.-0.06 ; \mathrm{I}^{2}=0 \% ; \mathrm{p}<0.01\right)$ and unprotected sex $\left(\mathrm{SMD}-0.44 ; 95 \% \mathrm{CI}-0.86\right.$ to $\left.-0.01 ; \mathrm{I}^{2}=79 \% ; \mathrm{p}=0.04\right)$ compared to interventions of a lesser time/intensity, however, moderate to high heterogeneity was reported. Such interventions could be included with other harm reduction approaches to prevent BBV transmission among PWID.

Resumen El tratamiento de sustitución de opiáceos y los programas de intercambio de jeringuillas han disminuido la transmisión de virus transmitidos por sangre (VTS) entre los usuarios de drogas inyectadas (UDI). Las intervenciones psicosociales podrían prevenir la transmisión de VTS. Mediante una revisión sistemática con meta-análisis, se estudió si las intervenciones psicosociales (p.e. CBT, entrenamiento en habilidades) redujeron los comportamientos de riesgo asociados a los VTS entre UDI, en comparación con las intervenciones control. Se incluyeron 32 y 24 ensayos clínicos aleatorizados en la revisión y meta-análisis, respectivamente (2000-mayo 2015 en MEDLINE, PsycINFO, CINAHL, Colaboración Cochrane y Clinical Trials, con una actualización en MEDLINE hasta diciembre de 2016). Las intervenciones psicosociales disminuyen los siguientes comportamientos de riesgo: compartir agujas/jeringuillas en comparación con la educación/información (DME -0.52; IC del 95\%: -1.02, $\left.-0.03 ; \mathrm{I}^{2}=10 \% ; \mathrm{p}=0.04\right)$ o en comparación con asesoramiento/pruebas para el VIH (DME - 0.24; IC del 95\%: $\left.-0.44, \quad-0.03 ; \quad \mathrm{I}^{2}=0 \%, \mathrm{p}=0.02\right) ; \quad$ compartir otros utensilios de inyección (DME -0.24 ; IC del 95\%: -0.42 , 







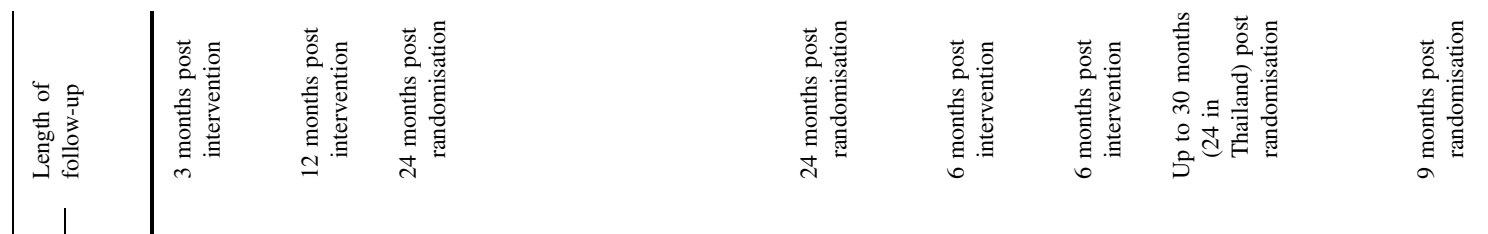

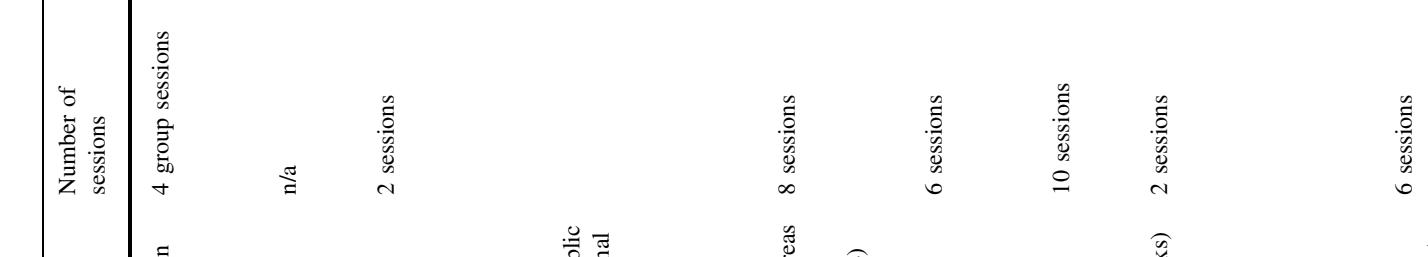

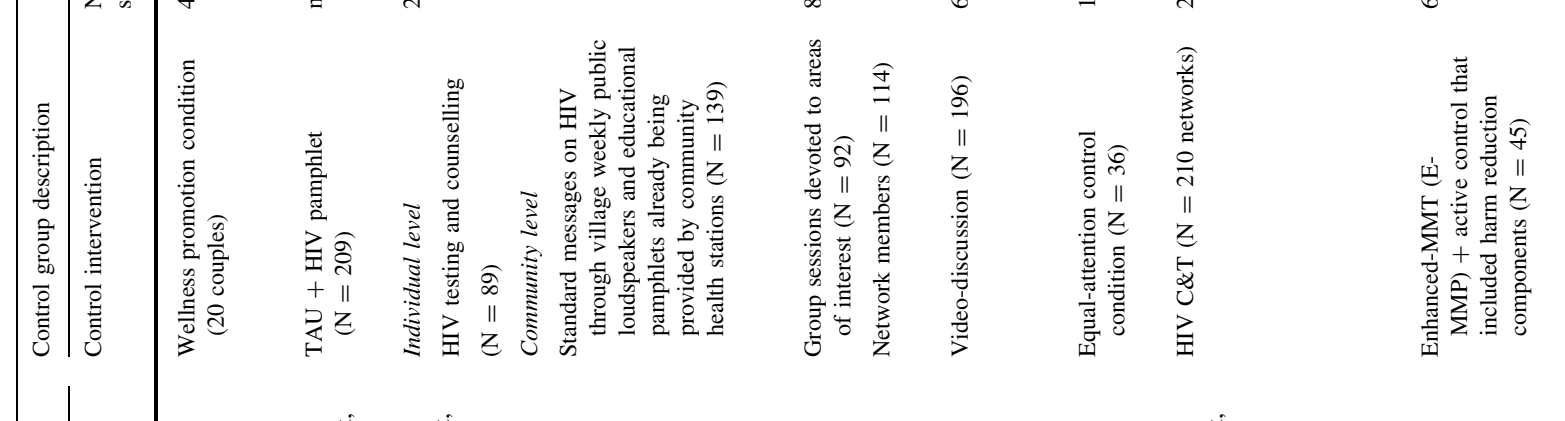

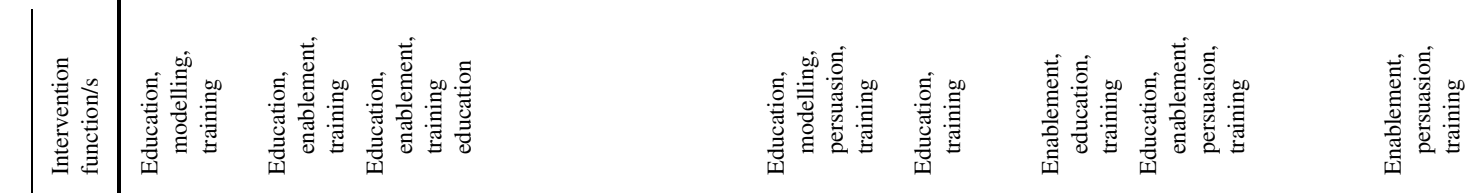

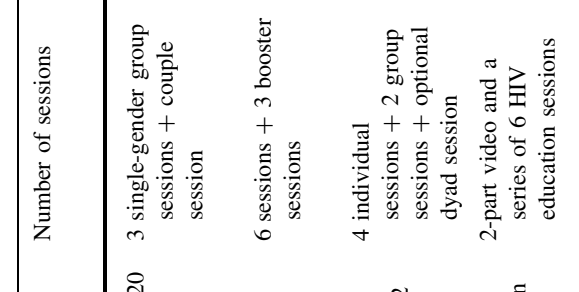

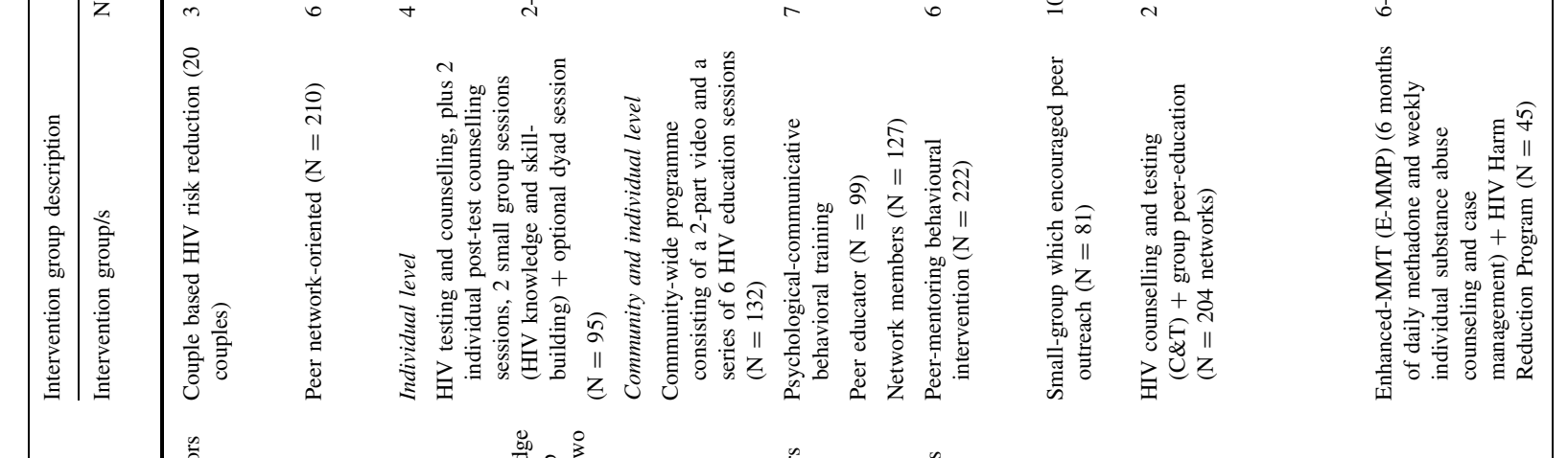

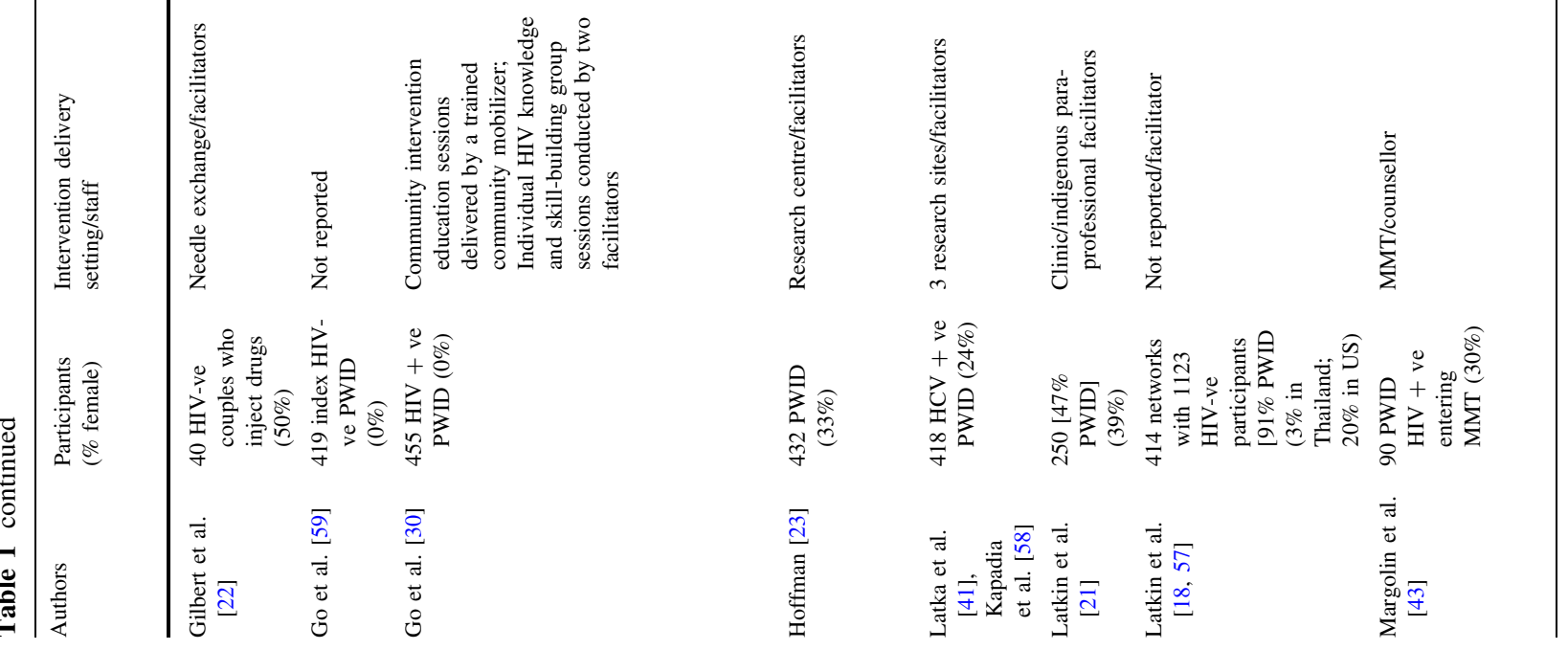




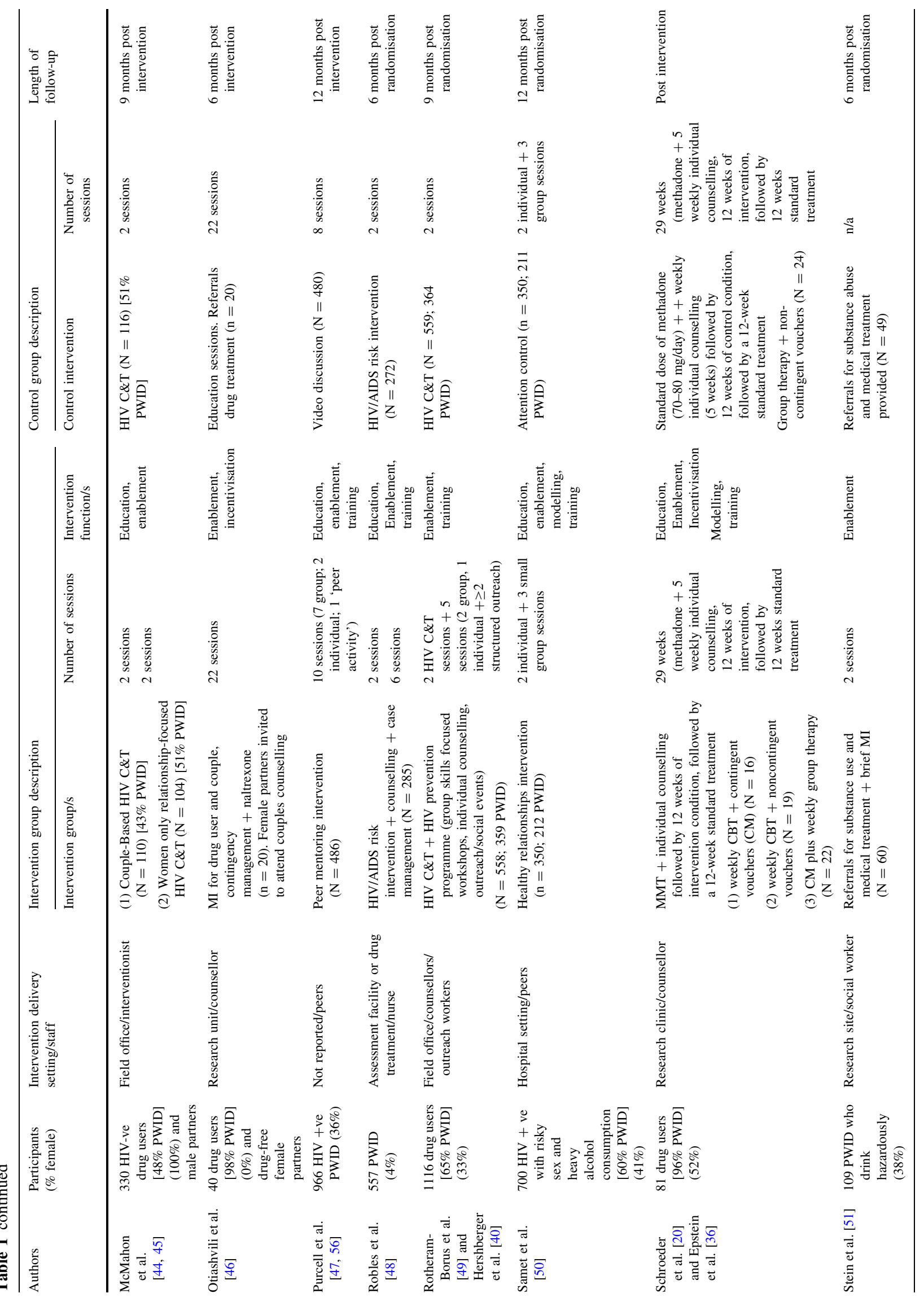




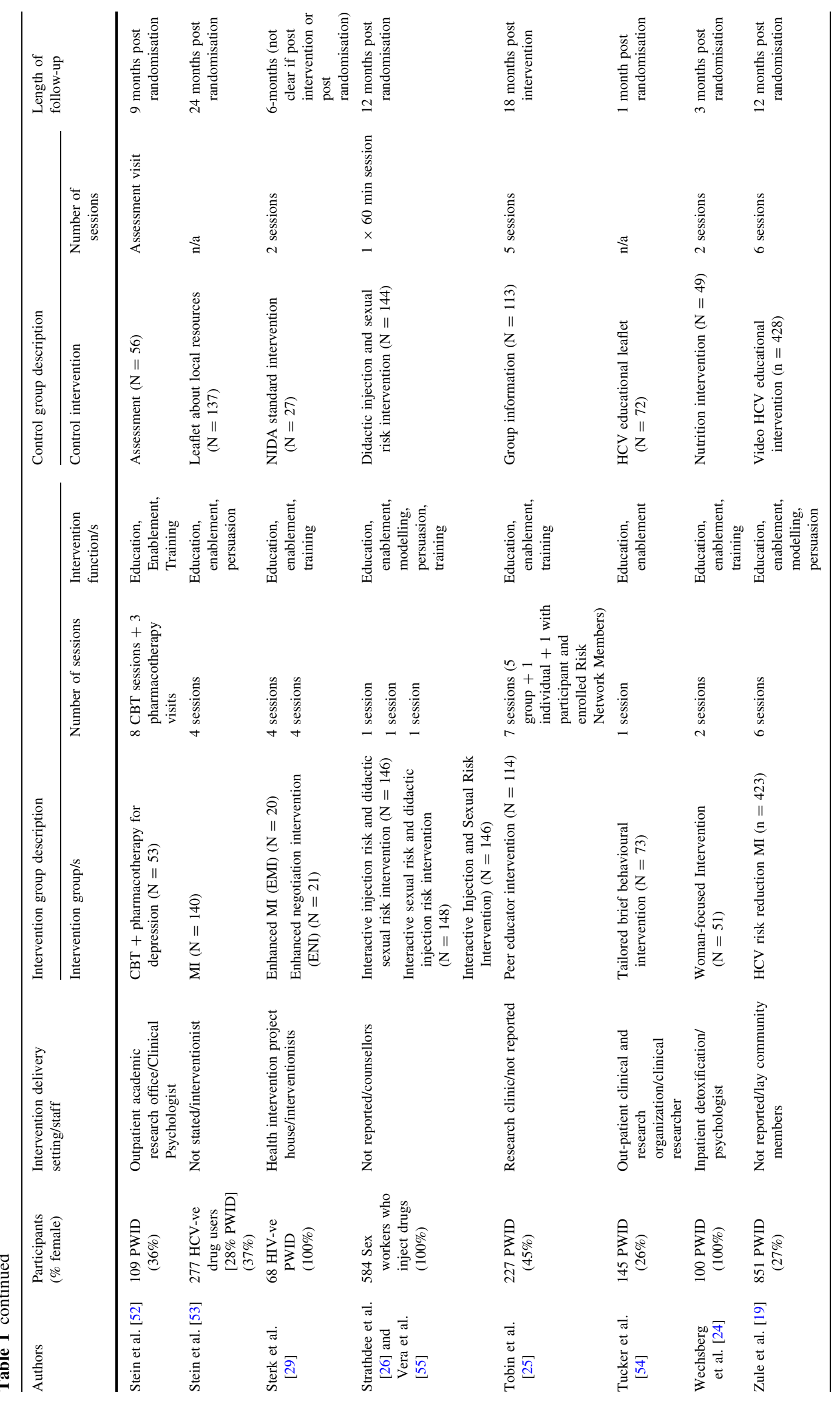


$\left.-0.06 ; \mathrm{I}^{2}=0 \% ; \mathrm{p}<0.01\right)$ y el sexo sin protección (DME -0.44 ; IC del 95\%: $-0.86,-0.01 ; \mathrm{I}^{2}=79 \% ; \mathrm{p}=0.04$ ) en comparación con las intervenciones de menor duración/ intensidad. Sin embargo, se ha detectado una heterogeneidad de moderada a alta. Tales intervenciones podrían incluirse junto con otros enfoques de reducción de daños para prevenir la transmisión de VTS entre los UDI.

Keywords People who inject drugs · Psychosocial intervention - Blood borne virus - Injecting risk behaviour . Sexual risk behaviour $\cdot$ Systematic review $\cdot$ Meta-analysis

\section{Introduction}

Among people who inject drugs (PWID), prevalence of the Hepatitis C virus (HCV) and HIV is around 5-90\% [1] and $<1-50 \%$ [2] respectively. While pre-exposure prophylaxis for HIV [3] and treatment for HCV are effective [4], no vaccine prevents $\mathrm{HCV}$. Opiate substitution therapy (OST) and needle exchanges effectively reduce HIV and HCV among PWID [5]. Psychosocial interventions (e.g. motivational interviewing, cognitive behavioural therapy and contingency management) could further decrease blood borne viruses (BBV) by educating PWID about transmission risks and developing strategies to avoid them.

Several systematic reviews and meta-analyses of psychosocial interventions to reduce BBV risk behaviours among drug users have reported modest effects [6-9]. Reviews conclude that harm reduction interventions, especially OST and needle exchange programmes, have reduced injecting risk behaviours, but have not prevented HCV transmission among PWID [5]. In addition, combined substance-use treatment and support for safe injection were most effective in reducing $\mathrm{HCV}$ seroconversion among PWID [6]. Interventions that target capability (i.e. individual's psychological and physical capacity to engage in the activity concerned including having the necessary knowledge and skills), opportunity (i.e. factors outside the individual that make the behaviour possible or prompt it), and motivation are thought to be more effective in addressing behaviour change than interventions that address one or fewer of these components [10]. In partial support of this, two reviews concluded that multi-session psychosocial interventions compared to educational interventions had minimal benefits on injecting risk behaviours [7] and modest benefits on sexual risk behaviours among people who use drugs [8]. In addition, large positive effects were reported compared to minimal interventions for reducing HIV sexual risk behaviours [8]. Despite these promising findings, another review concluded that behavioural interventions (peer-intervention training and counselling interventions) were "unlikely ... $[$ to $]$ have a considerable effect on HCV transmission" for PWID (p. 176) [9].

PWID are more likely to have BBV than people who use drugs but do not inject [11]. Alongside elevated risks from sharing injecting equipment, some PWID report greater high-risk sexual behaviours, including sex trading, multiple sex partners and sex without a condom, than people who use drugs but do not inject [11-14].

\section{Objective}

This systematic review and meta-analysis sought to examine whether psychosocial interventions could reduce injecting and sexual risk behaviours compared to usual care; education or information; HIV testing and counselling; or interventions of lesser time or intensity (with and without OST).

\section{Methods}

A systematic review with meta-analysis was conducted in accordance with the Preferred Reporting Items for Systematic Reviews and Meta-Analyses [15] and registered with the International Prospective Register of Systematic Reviews (PROSPERO 014:CRD42014012969).

\section{Search Strategy}

The search strategy is described in Table I of the Supplementary Online document. The following databases were searched for relevant randomised controlled trials (RCTs) published from 2000 until 26 May 2015: MEDLINE, PsycINFO, CINAHL and the Cochrane Collaboration, with an update search in MEDLINE to 9 December 2016. Additionally, Clinical Trials databases were searched to identify additional publications. Forward and backward searching of references was conducted and reference lists of recent relevant reviews were cross-checked to verify all relevant RCTs were included in the current systematic review.

\section{Eligibility}

Citations were included if full text was published in English. Studies were eligible if (1) published during 2000-2016; (2) participants were PWID or results presented for PWID; (3) they were RCTs; (4) outcome/s included: (i) any injecting risk behaviour including sharing of needle/syringes or other injecting paraphernalia, and injecting frequency, reported separately or as an aggregated outcome, (ii) any sexual risk behaviour including unprotected sex or number of sexual partners, reported separately 
or as an aggregated outcome; and (5) psychosocial interventions were compared to a control group, who received usual care, education or information, HIV testing and counselling, "an intervention of lesser time or intensity" [9] (with and without OST).

GG and NM independently assessed all abstracts and potentially eligible full-text manuscripts against eligibility criteria. Where disagreement regarding study inclusion occurred, decisions were reached through referral to additional reviewers, $\mathrm{EH}, \mathrm{DS}, \mathrm{KW}$.

\section{Data Extraction}

DS, KW, JM, and GG extracted the following data on each study using a checklist: authors, publication year, country, aim of intervention, participants (\% PWID, \% females, and mean age), intervention delivery setting/staff, intervention description, adherence, description of control interventions, follow-up duration and results (Table 1). These data were verified by a second reviewer and differences resolved through discussion.

\section{Methodological Quality}

Two authors (from GG, DS, JM, JT) independently assessed the trial's methodological quality across six domains using the Cochrane Risk of Bias tool [16]: sequence generation; allocation concealment; blinding of participants, personnel, and outcome assessors; incomplete outcome data; selective outcome reporting; and other sources of bias (Fig. 2). Assessments were compared to quality assessments from published reviews [5-7, 9], and differences resolved through discussion with a third assessor, EH.

\section{Intervention Descriptions}

Intervention functions were categorised using The Behaviour Change Wheel [10], including: education (increasing knowledge/understanding), e.g. "The $30 \mathrm{~min}$ pre-test counseling session provided basic information about...how to reduce the risk of HIV" [17], persuasion (using communication to induce positive/negative feelings/stimulate action) e.g. "facilitators...praise[d] their effective communication strategies" [18] and "reaffirmed commitment to change" [19], incentivisation (creating expectation of reward), e.g. "Contingent vouchers were given when a participant provided a cocaine-negative urine specimen" [20], training (imparting skills), e.g. "skills building to teach personal risk reduction and negotiation" [21] and "technical condom use and syringe disinfection skills" [22], modelling (providing example/s for people to aspire to/imitate), e.g. "model injection and sexual risk reduction behaviors with their risk network members" [23] and "demonstration and rehearsal of syringe cleaning" [19], and enablement (increasing means/reducing barriers) e.g. "women created a personalized risk-reduction plan" [24], "goal-setting for HIV risk reduction" [25] and role play "to help identify barriers to safer injection" [26] (Table 1). Functions that related directly to the intervention's target behaviour/s were coded. GG and DS independently determined intervention functions. Disagreements were resolved through discussion. Intervention functions assigned to five trials were validated by a behaviour change expert.

\section{Statistical Analysis}

The principal summary measure was the standardized mean difference (SMD). As outcome data were presented as dichotomous or continuous data across included RCTs, odds ratios (OR) were recalculated as SMD to allow data pooling. The standard errors of $\log$ OR were converted to standard errors of a SMD by multiplying by the same constant $(\sqrt{ } 3 / \pi=0.5513)$. This allowed the standard error for the $\log$ OR and hence a confidence interval (CI) to be calculated. For each RCT, the SMD and corresponding 95\% CIs for the assessed outcome were retrieved or calculated [27]. Data entry and statistical analysis were performed using Review Manager Software. Where RCTs reported data from various follow-up periods, data from the latest follow-up period were included in the meta-analysis, combining outcomes assessed at multiple time periods. To determine whether RCTs included in the meta-analysis were consistent, the degree of heterogeneity was calculated. $I^{2}$ of $25 \%$ was considered low, $50 \%$ moderate and $75 \%$ high heterogeneity [28]. In the inverse variance method, individual effect sizes were weighted according to the reciprocal of their variance calculated as the square of the standard error.

\section{Main and Subgroup Analysis}

In line with a recent Cochrane review [7] and in an attempt to address the complexity of clinical heterogeneity of interventions, sub-group analyses were conducted to compare psychosocial interventions with (1) treatment as usual; (2) education or information; (3) HIV testing and counselling; and (4) control interventions of lesser time or intensity with and (5) without OST. As follow-up duration may affect intervention effectiveness, further sub-group analyses were conducted where possible, comparing length of time in months from the end of the intervention to the final follow-up of included trials (i.e. $\leq 3,4-6$, and $\geq 9$ months follow-up).

Where RCTs included in the meta-analyses had more than one intervention group [17, 20, 29], data from the 
psychosocial intervention most relevant to the aims of this systematic review were compared to the control intervention. For Booth et al. [17], the most relevant intervention condition was considered treatment as usual (TAU) + $\mathrm{HIV} / \mathrm{HCV}$ counselling and education (C\&E), rather than $\mathrm{TAU}+$ a therapeutic alliance to facilitate treatment entry. For Sterk et al. [29], the enhanced negotiation intervention (ENI) was considered more relevant than the enhanced motivation intervention (EMI). For Schroder et al. [20], TAU+ weekly $\mathrm{CBT}+$ contingent vouchers (CM) $(\mathrm{CBT}+\mathrm{CM})$ was considered superior to both weekly $\mathrm{CBT}+$ noncontingent vouchers and $\mathrm{CM}+$ weekly group therapy, and therefore selected as the intervention condition for the meta-analysis. Go et al. [30] conducted a multilevel intervention using a $2 \times 2$ (four-arm) factorial design consisting of: (1) standard of care (i.e. HIV testing and counselling); (2) structural-level community stigma reduction programme; (3) individual-level post-test counselling and skill-building support groups; (4) both individual and structural level activities. For the purpose of this systematic review, the individual-level post-test counselling and skill-building support groups will be compared to individual standard of care.

Random effect models were applied to compare the following outcomes of interest for meta-analysis by type of control intervention, and by type of control intervention and length of follow-up post intervention: any injecting risk behaviour (Fig. 3a; Table 2) including sharing of needle/syringes (Fig. 3b; Table 2) or other injecting paraphernalia (Fig. 3c; Table 2), and frequency of injecting (Fig. 3d; Table 2), reported separately or as an aggregated outcome; and any sexual risk behaviour (Fig. 4a; Table 3) including unprotected sex (Fig. 4b; Table 3) or number of sexual partners (Fig. 4c; Table 3), reported separately or as an aggregated outcome.

\section{Results}

\section{Study Selection}

Database searches to 26 May 2015 resulted in 2493 citations; an additional 77 citations were identified from 1 January 2015 to 9 December 2016 (Fig. 1). One additional manuscript was identified from hand-searching other reviews' reference lists. After removal of duplicates, 1903 citations remained. In total, 1771 abstracts were excluded as they did not meet eligibility criteria and 132 abstracts were selected for full-text assessment, including four related manuscripts referenced in these selected texts. Eighty-nine articles were excluded as: they were not RCTs $(n=34)$; outcomes of interest were not assessed/presented $(n=29)$; outcomes were not presented by PWID $(n=6)$; number of PWID was not reported $(n=4)$; or the intervention was not psychosocial $(\mathrm{n}=4)$. Additionally, ten manuscripts were excluded as intervention group outcomes were not compared or did not evaluate the intervention's effect. One further manuscript was excluded because both treatment arms received the same psychosocial intervention; the intervention arm received a 90-day free OST coupon. One manuscript published in Chinese was excluded [a full list of excluded references available on request].

Forty-two manuscripts from 32 RCTs were eligible [17-26, 29-55]. The meta-analyses included 24 trials [17-22, 24, 25, 29-31, 33, 38, 39, 41, 43, 46-52, 54]. Eight trials were excluded from the meta-analysis for: not providing the number of PWID for control and intervention groups at follow-up [32, 34, 35, 45, 53], only providing risk ratios [37], outcome combined HIV with sexually transmitted infections [26] and data for 'unsafe injection practices' was only presented at baseline [23].

\section{Quality Assessment}

Risk of bias varied across RCTs (Fig. 2). Incomplete outcome data was the most common risk of bias, but selective outcome reporting contributed to risk of bias for some trials. Other potential sources included altering randomisation protocols depending on number of participants enrolled on a particular day [41], significant baseline differences between groups in outcome of interest [31], variation in the TAU group across sites [17]; possible cross-over contamination between groups $[18,24,38,39,41,50]$, a high proportion of excluded individuals who differed significantly to those included [20], and large variations reported in follow-up period [23].

\section{Study Characteristics}

Characteristics of included RCTs are described in Table 1 (and more detail is presented in the Online Supplementary document Table II). In total, 12,840 participants (35\% female; range 0-100\%) were enrolled; the majority were PWID (84.5\%) (range 16-100\%). Most trials $(\mathrm{n}=18)$ were conducted in the US [17, 19-21, 25, 29, 32, 34, 35, 38, 41, 43, 45, 47, 49, 51-53]; three in Russia [23, 24, 50]; two in Canada [33, 37]; two in Vietnam [30, 39]; and one in Kazakhstan [22]; Georgia [46]; Australia [54]; the UK [31]; Mexico [26]; and Puerto Rico [48]. One trial was conducted in both the US and Thailand [18].

Trials included in the systematic review compared psychosocial interventions with usual care $(n=4)$ $[17,37,51,52]$, education or information $(\mathrm{n}=9)$ $[19,25,26,33,34,39,46,53,54]$, HIV testing and counselling $(n=5)[18,30,45,48,49]$, interventions of lesser time or intensity with $(\mathrm{n}=12)$ $[21-23,29,31,32,35,38,41,47,50]$ and without OST $(\mathrm{n}=2)[20,43]$. 


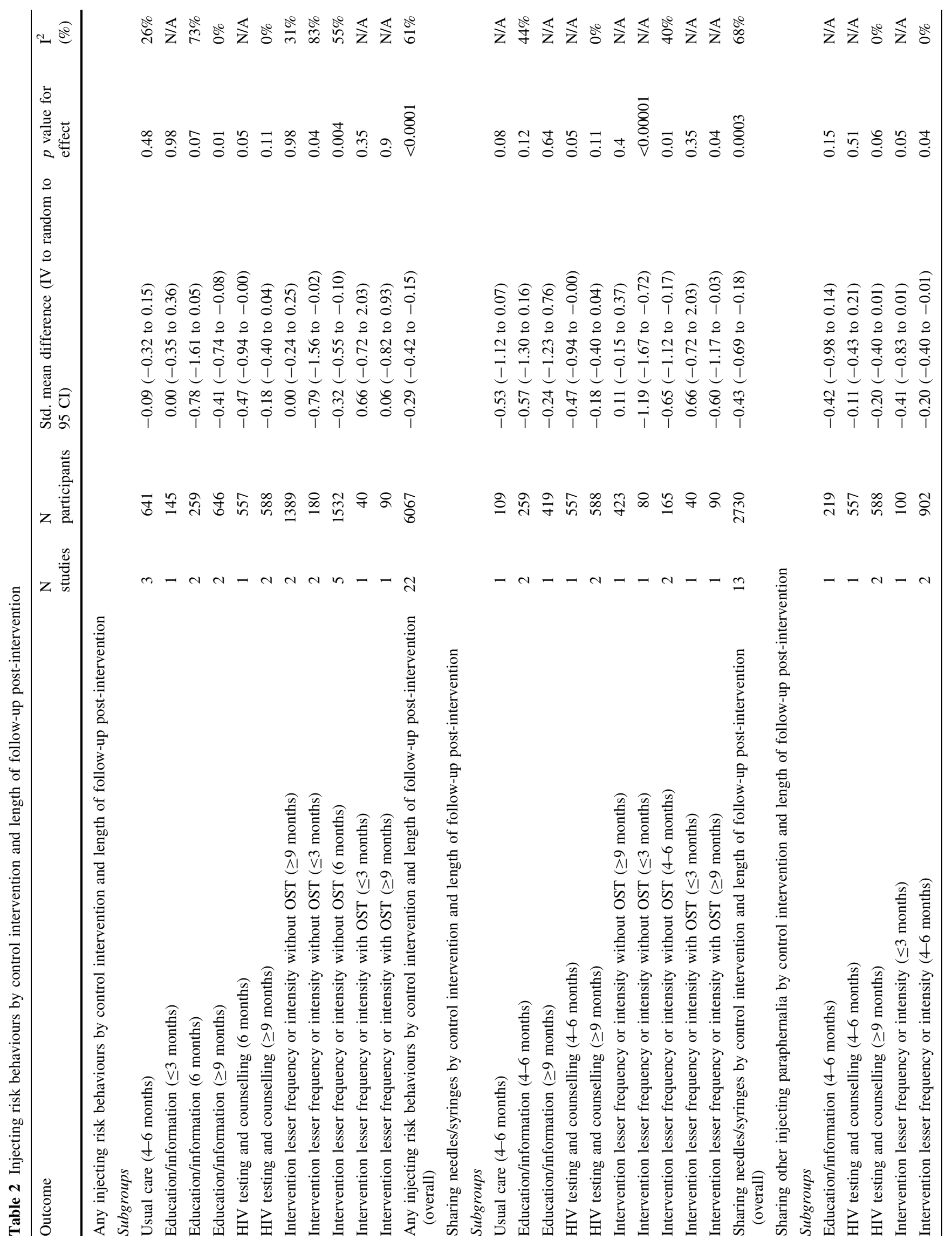




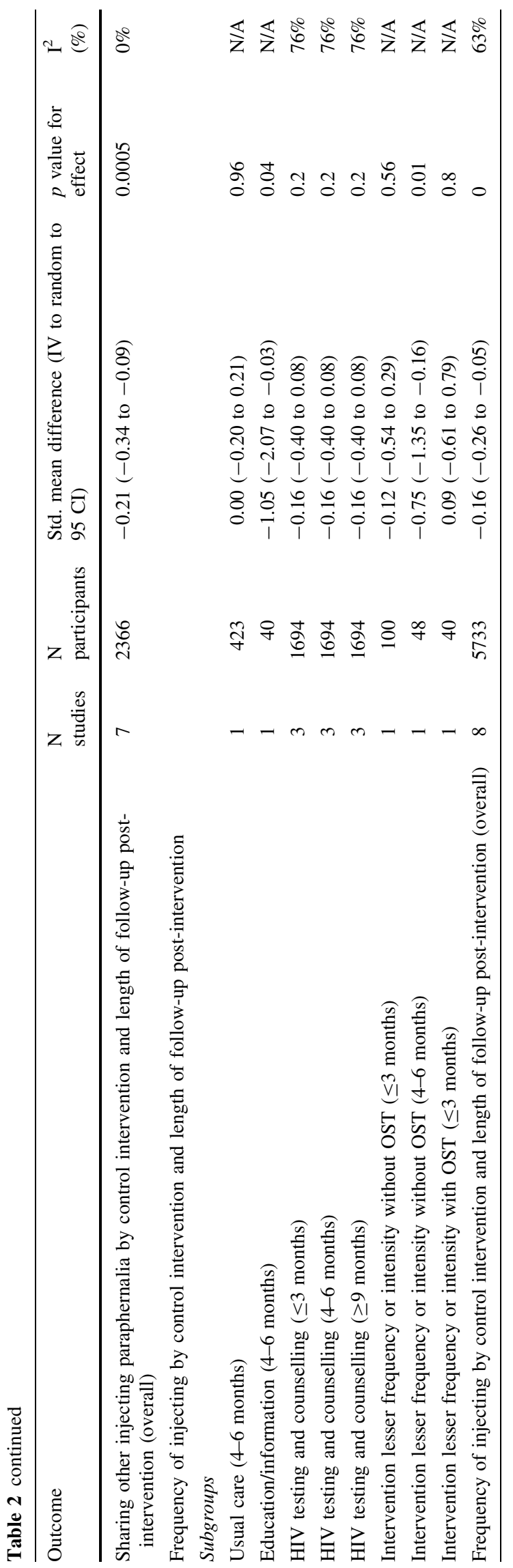

Of the 32 interventions delivered in the RCTs, most $(\mathrm{n}=14)$ were delivered to individual participants $[17,19,20,24,26,29,31,33,37,48,51-54]$; eight were delivered to groups $[18,23,32,34,38,39,41,49]$ and two to couples $[35,45]$. The remaining eight trials delivered interventions in a combination of ways e.g. individual and couples sessions[46]; individual and group sessions [18, 25, 43, 47, 50]; group and couples sessions [22] and one trial provided both individual and structural level activities [30]. For interventions with more than one session, retention or adherence to the intervention ranged from 50\% [17] to 95\% [29] (further detail provided in the Online Supplementary Table II).

Eight interventions incorporated peer mentoring from an index participant to change the behaviours of other PWID $[18,21,23,25,38,39,41,47,49]$. The majority of interventions contained at least three sessions $(\mathrm{n}=25)$ [18, 20-23, 25, 29-32, 34, 35, 37-39, 41, 43, 46-50, 52, 53], four interventions contained two sessions [17, 24, 44, 51] and three interventions one session [26, 33, 54].

On the whole, interventions were delivered in drug treatment settings including outpatient and hospital clinics [20, 21, 31, 48-50]; methadone maintenance clinics [32, 43]; inpatient or residential detoxification units [17, 24, 54]; needle and syringe exchanges [22, 37] or outreach [49] (settings not mutually exclusive). In addition, the vast majority of studies were delivered by clinic staff in the treatment setting as opposed to researcher delivered (or not specified) (Table 1).

\section{Outcomes}

Various validated and other purposely developed instruments were used to assess injecting behaviour in 32 trials [17-26, 29-35, 37-39, 41, 43, 45-52, 54] and sexual behaviour in 24 trials [17-26, 29-32, 34, 35, 38, 39, 43, 45, 47, 49, 50, 54]. The most common reporting timeframe for outcomes was in the past 30 days $(\mathrm{n}=19) \quad[17, \quad 18, \quad 22-26, \quad 29, \quad 32-34$, $43,46,48-52,54]$, followed by the past 3 months $(\mathrm{n}=10)$ $[23,30,32,35,38,39,41,45,47,50]$ or 6 months $(\mathrm{n}=3)$ $[21,25,53]$, past week $(n=2)[20,37]$ or behaviour at the last sexual encounter or injecting event $(\mathrm{n}=1)$ [19] (answers not mutually exclusive as three trials reported different reporting timeframe for different outcomes) $[23,25,50]$.

\section{Results of Individual RCTs Not Included in the Meta-analyses}

Of the eight trials omitted from the meta-analyses, three reported that psychosocial interventions showed greater reductions in injecting risk behaviours than education/information, usual care or HIV testing and counselling $[26,37,45]$ and three reported that psychosocial interventions showed greater reductions in sexual risk behaviours than or HIV testing and counselling [32, 35, 45]. 


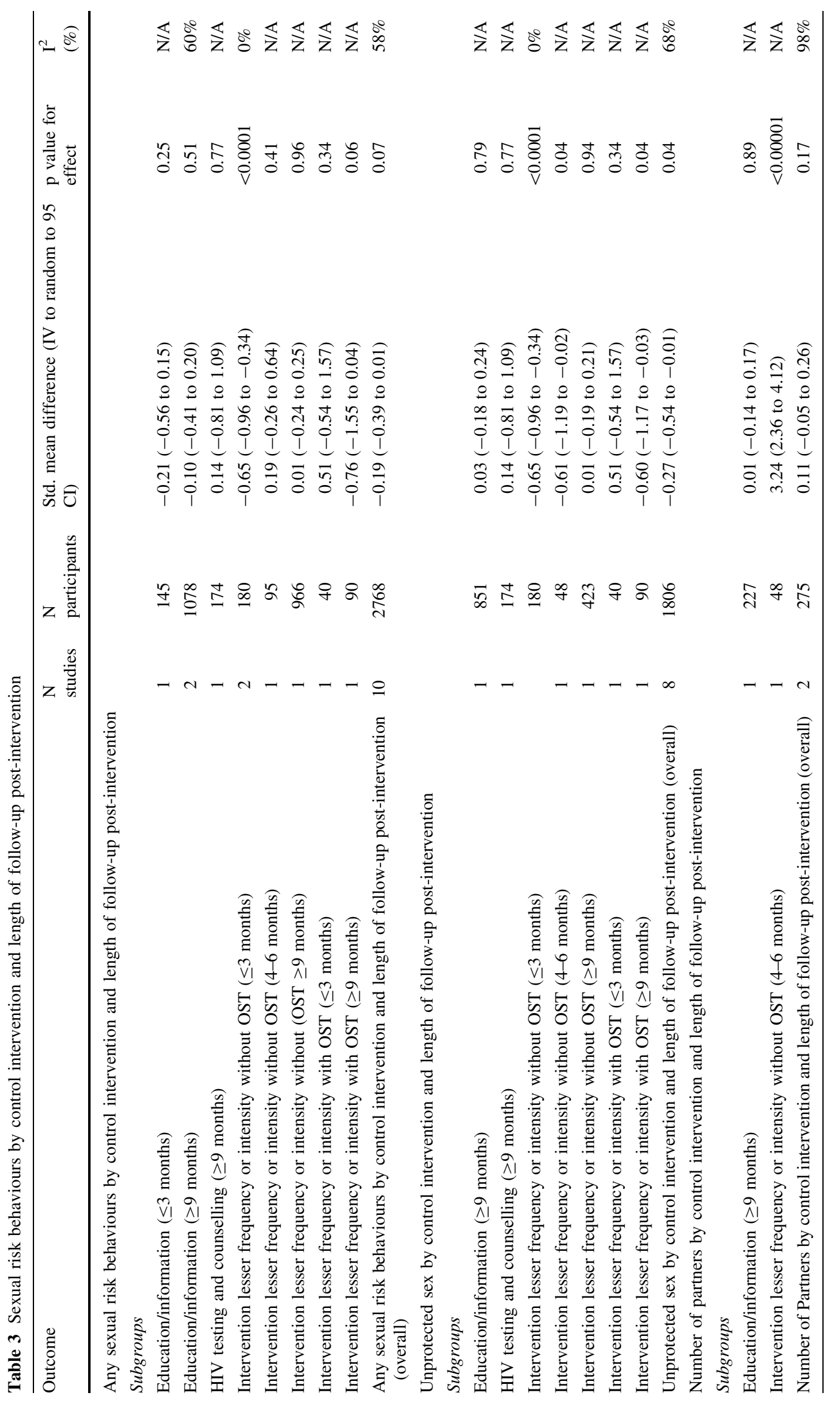




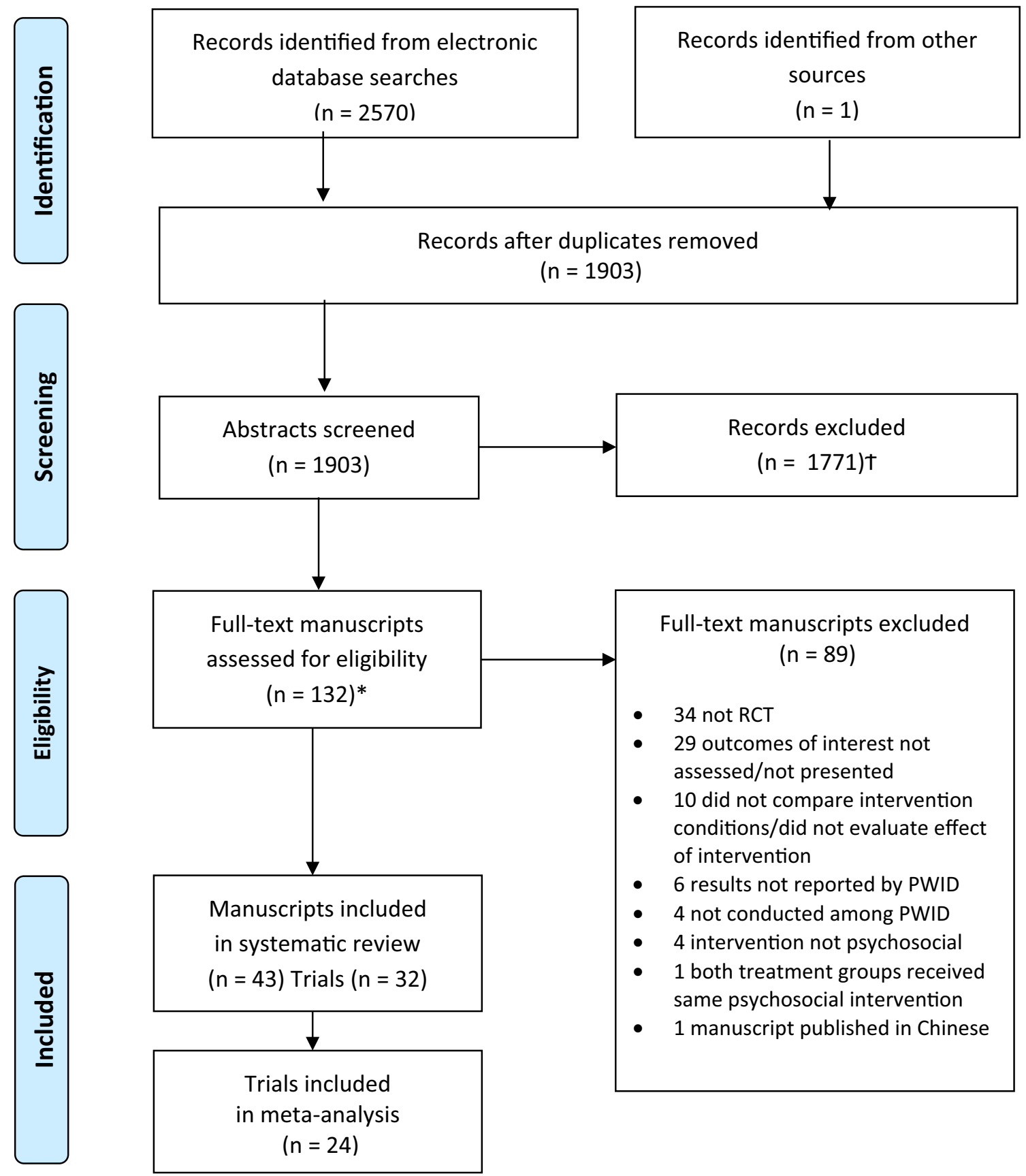

$\uparrow$ Includes 6 trials listed in the clinical trials database for which no published papers could be found.

* Includes 4 related manuscripts referenced in potentially eligible manuscripts

Fig. 1 Flowchart. $\dagger$ Includes 6 trials listed in the clinical trials database for which no published papers could be found. *Includes 4 related manuscripts referenced in potentially eligible manuscripts

\section{Meta-analyses}

\section{Any Injecting Risk Behaviour}

Twenty-two RCTs assessed any injecting risk behaviour (Fig. 3a). Psychosocial interventions independently reduced injecting risk behaviours more than control interventions in seven trials [21, 22, 25, 38, 41, 46, 48]. A total of 3096 and 2971 PWID were included in the intervention and control groups respectively. Overall, psychosocial interventions showed a greater reduction in any injecting risk behaviour (SMD $-0.29 ; 95 \% \mathrm{CI}-0.42$ to $\left.-0.15 ; \mathrm{I}^{2}=61 \% ; \mathrm{p}=<0.01\right)$ than control interventions (Fig. 3a). Psychosocial interventions also demonstrated 


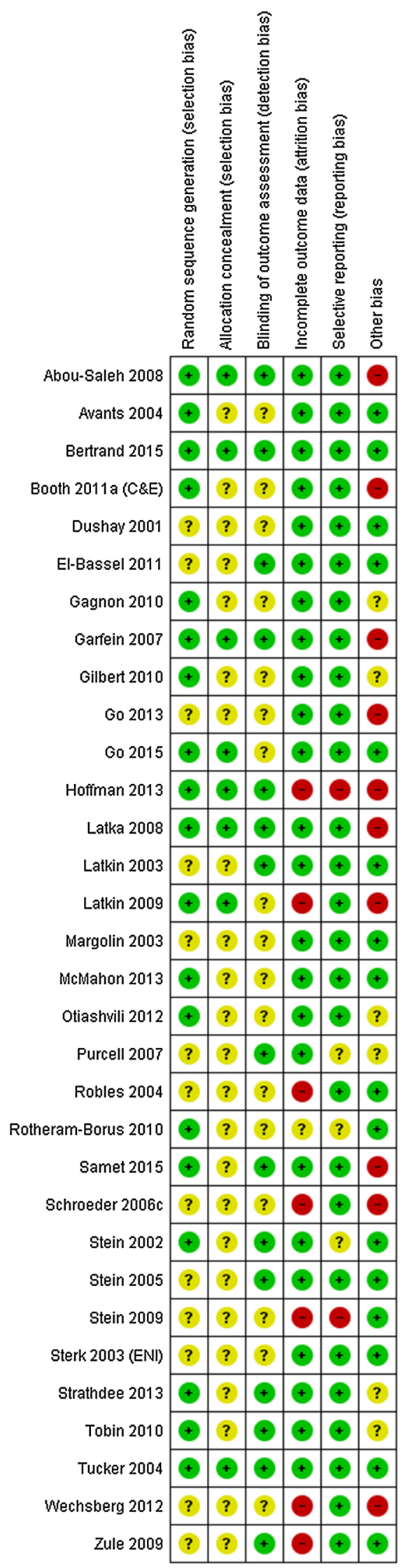

Fig. 2 Risk of bias for included trials greater reductions in any risk behaviours than education/ information (SMD $-0.41 ; 95 \%$ CI -0.79 to -0.04 ; $\mathrm{I}^{2}=62 \% ; \mathrm{p}=0.03$ ); HIV testing and counselling (SMD $-0.24 ; 95 \%$ CI -0.44 to $-0.03 ; \mathrm{I}^{2}=0 \% ; \mathrm{p}=0.02$ ); interventions of a lesser time or intensity (SMD -0.34 ; $95 \%$ CI -0.56 to $-0.12 ; \mathrm{I}^{2}=75 \% ; \mathrm{p}<0.01$ ), but no difference was found when compared with interventions of a lesser time or intensity that included OST (SMD 0.23; 95\% CI $0.51-0.97 ; \mathrm{I}^{2}=0 \% ; \mathrm{p}<0.01$ ) or treatment as usual (SMD $-0.09 ; 95 \%$ CI -0.32 to $0.15 ; \mathrm{I}^{2}=26 \%$; $\mathrm{p}=0.54$ ). Where outcomes were assessed $\leq 3$ or 4-6 months post-intervention, psychosocial interventions reduced any injecting risk behaviour when compared with interventions of lesser time or intensity. Where outcomes were compared $\geq 9$ months post-intervention, psychosocial interventions reduced any injecting risk behaviour more than interventions that provided education/information alone (Table 2). Heterogeneity was moderate in psychosocial interventions compared to education/information $\left(\mathrm{I}^{2}=62 \%\right)$, possibly due to the variations in the mode of delivery and intervention components (Table 1). The education/information interventions in the control conditions included a pamphlet compared to a 6 session education/ enablement intervention [39] and ranged from comparing a one-session education intervention with a one-session motivational intervention [33], to comparing 22 education sessions with referrals to drug treatment with a 22 -week intervention including motivational interviewing counseling sessions for both the male participant and the couple, monetary incentives for drug abstinence, and researchsupported detoxification followed by naltrexone treatment [46]. There was high heterogeneity in the analysis of psychosocial interventions compared to interventions of a lesser time or intensity (without OST) $\left(\mathrm{I}^{2}=75 \%\right)$ for similar reasons to those mentioned above. Six trials included equal-attention control conditions ranging from 2 [24] to 10 [41] sessions, and three included control interventions with fewer sessions, ranging from four versus one session [31] to ten versus eight sessions [47] (Table 1). All but one trial [31] had at least two sessions in the control and/or intervention conditions. One trial compared a twosession woman focused intervention with a two-session nutritional intervention [24]. The variation in intervention duration and content across conditions contributes to the high heterogeneity.

\section{Sharing Needles and Syringes}

Thirteen RCTs assessed sharing of needles/syringes (Fig. 3b). Psychosocial interventions reduced this behaviour more than the control interventions in five of those trials [21, 22, 43, 46, 48]. A total of 1411 and 1315 PWID were included in the intervention and control groups 


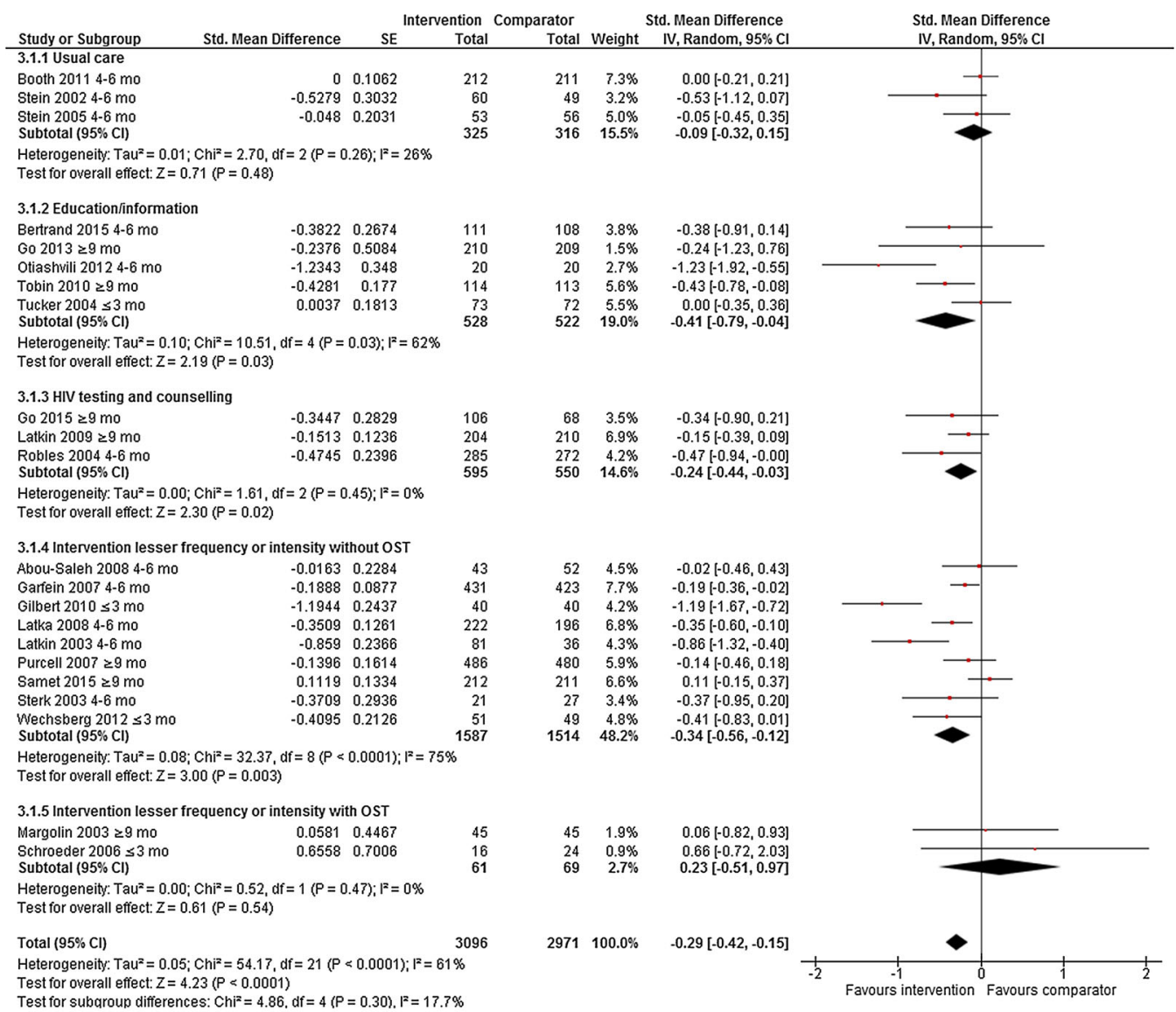

(a)

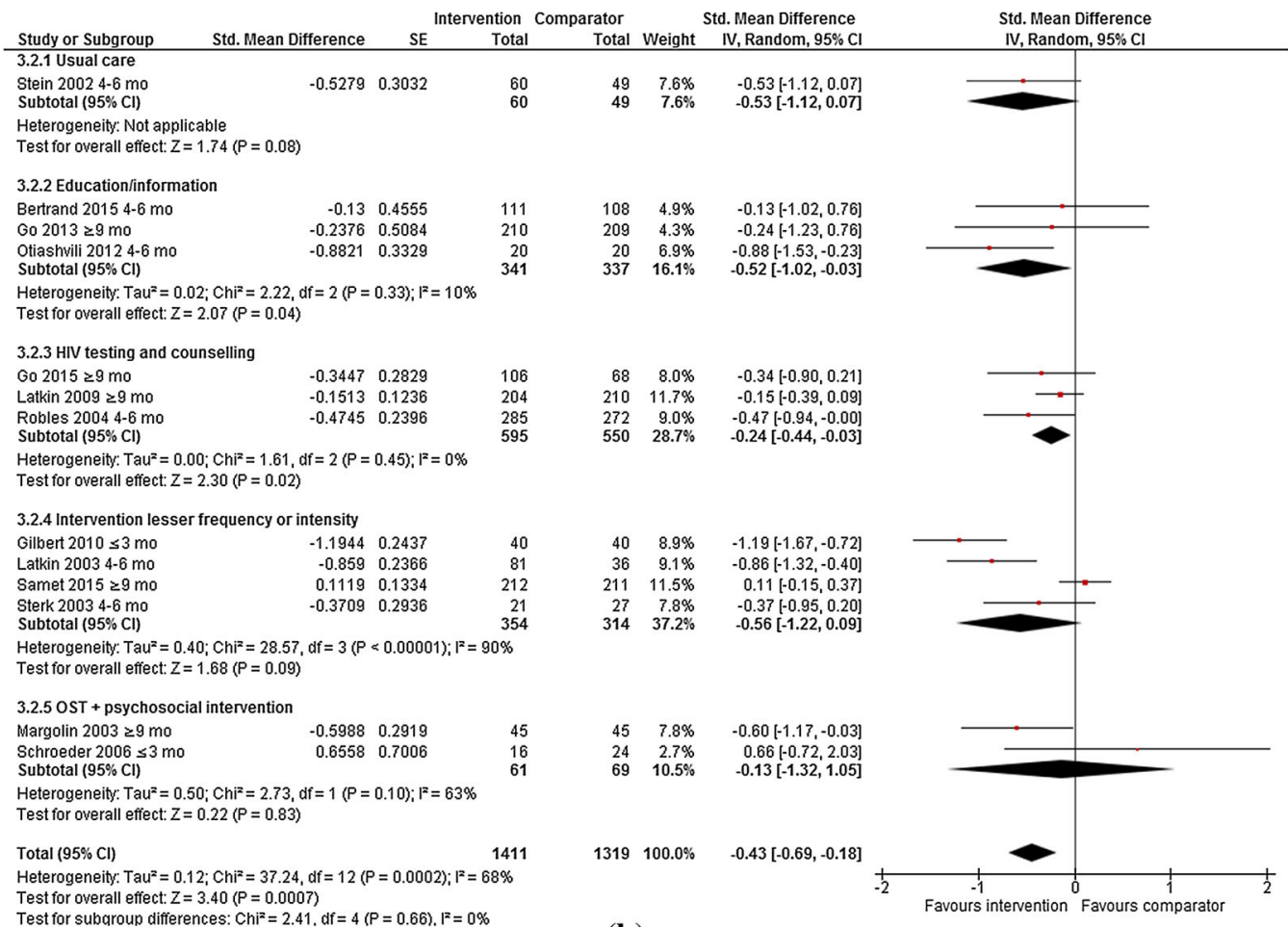


4Fig. 3 Efficacy of psychosocial interventions versus control interventions in reducing a ANY injecting risk behaviours among people who inject drugs, $\mathbf{b}$ sharing of needles or syringes among people who inject drugs, c sharing of other injecting equipment (not needle/ syringes) among people who inject drugs, $\mathbf{d}$ frequency of injecting among people who inject drugs

respectively. Overall, psychosocial interventions reduced the sharing of needle/syringes (SMD $-0.43 ; 95 \%$ CI -0.69 to $\left.-0.18 ; \mathrm{I}^{2}=68 \% ; \mathrm{p}<0.01\right)$ compared with control interventions. Psychosocial interventions reduced needle and syringe sharing compared with education/information (SMD $-0.52 ; 95 \%$ CI -1.02 to $-0.03 ; \mathrm{I}^{2}=10 \%$; $\mathrm{p}=0.04$ ); or HIV testing and counselling (SMD -0.24 ; $95 \% \mathrm{CI}-0.44$ to $-0.03 ; \mathrm{I}^{2}=0 \%$; $\mathrm{p}=0.02$ ); but no difference was found when compared with interventions of a lesser time or intensity (SMD $-0.56 ; 95 \%$ CI -0.12 to $\left.0.09 ; \mathrm{I}^{2}=90 \% ; \mathrm{p}=0.09\right)$, interventions of a lesser time or intensity that included OST (SMD -0.13; 95\% CI $\left.-1.32,1.05 ; \mathrm{I}^{2}=63 \% ; \mathrm{p}=0.83\right)$ or treatment as usual (SMD $-0.53 ; 95 \% \mathrm{CI}-1.12$ to $0.07 ; \mathrm{p}=0.08$; one trial). Where outcomes were assessed $\leq 3$ or $4-6$ months postintervention, psychosocial interventions reduced needle and syringe sharing more than interventions of lesser time or intensity. Where outcomes were assessed 4-6 months post-intervention, a greater reduction in any injecting risk behaviour was found for psychosocial interventions compared with HIV testing and counselling (Table 2). There was moderate and high heterogeneity in the analysis of psychosocial interventions compared to interventions of a lesser time or intensity with $\left(\mathrm{I}^{2}=63 \%\right)$ and without OST $\left(\mathrm{I}^{2}=90 \%\right)$, again potentially explained by the differences in intervention content and delivery. The two trials that compared psychosocial interventions with OST to interventions of a lesser time/intensity with OST varied in length of OST treatment. Both included a 12-week psychosocial intervention, however, the trial where methadone was prescribed for six months independently reduced needle and syringe sharing [43] and the trial that prescribed methadone for three months did not [20]. Four trials compared psychosocial interventions with interventions of a lesser time or intensity without OST, two delivered to couples [22] or encouraged peer outreach [21] independently reduced needle and syringe sharing, whereas those delivered to individuals on their own or in groups did not $[29,50]$.

\section{Sharing Other Injecting Paraphernalia}

Seven RCTs assessed sharing of injecting paraphernalia (other than needles/syringes) (Fig. 3c). None independently found the psychosocial intervention to be more efficacious than the control interventions. A total of 1209 and 1157 PWID were included in the intervention and control groups respectively. Overall, psychosocial interventions showed greater reductions in the sharing of other injecting paraphernalia (SMD $-0.21 ; 95 \% \mathrm{CI}-0.34$ to $-0.09 ; \mathrm{I}^{2}=0 \%$; $\left.\mathrm{p}<0.01\right)$ compared with control interventions. Psychosocial interventions reduced the sharing of other injecting paraphernalia more than interventions of a lesser time or intensity without OST (SMD $-0.24 ; 95 \% \mathrm{CI}-0.42$ to $-0.06 ; \mathrm{I}^{2}=0 \%$; $<<0.01$ ); but no differences were found when compared with education/information (SMD $-0.42 ; 95 \% \mathrm{CI}-0.98$ to $0.14 ; \mathrm{p}=0.15$; one trial); and HIV testing and counselling (SMD $-0.17 ; 95 \% \mathrm{CI}$ -0.34 to $\left.0.00 ; \mathrm{I}^{2}=0 \% ; \mathrm{p}=0.05\right)$. Where outcomes were compared 4-6 months post-intervention, psychosocial interventions significantly reduced sharing of other injecting paraphernalia compared with interventions of lesser time or intensity (Table 2).

\section{Injecting Frequency}

Eight RCTs assessed frequency of injecting (Fig. 3d). Psychosocial interventions independently reduced frequency of injecting compared with the control interventions in four trials [29, 46, 48, 49]. A total of 1168 and 1177 PWID were included in the intervention and control groups respectively. Overall, psychosocial interventions showed no difference in reducing frequency of injecting (SMD $-0.17 ; 95 \%$ CI -0.35 to $0.00 ; \mathrm{I}^{2}=61 \%$; $\mathrm{p}=0.05)$. Psychosocial interventions significantly reduced the frequency of injecting compared with education/information (SMD - 1.05; 95\% CI -2.07 to $-0.03 ; \mathrm{p}=0.04$; one trial); but no difference was found when compared with interventions of a lesser time or intensity with (SMD $0.09 ; 95 \% \mathrm{CI}-0.61$ to $0.79 ; \mathrm{I}^{2}=76 \% ; \mathrm{p}=0.20$; one trial) and without OST (SMD $-0.46 ; 95 \% \mathrm{CI}-1.02$ to $\left.0.21 ; \mathrm{I}^{2}=66 \% ; \mathrm{p}=0.80\right) ; \mathrm{HIV}$ testing and counselling (SMD $-0.16 ; 95 \% \mathrm{CI}-0.40$ to $0.08 ; \mathrm{I}^{2}=76 \% ; \mathrm{p}=0.20$ ) and treatment as usual (SMD $-0.00 ; 95 \% \mathrm{CI}-0.20$ to $0.21 ; \mathrm{p}=0.96$; one trial). Where outcomes were compared 4-6 months post-intervention, the frequency of injecting significantly reduced for participants receiving psychosocial interventions compared with participants receiving education/information (Table 2). There was moderate to high heterogeneity in the analysis comparing psychosocial interventions to HIV testing and counselling $\left(\mathrm{I}^{2}=76 \%\right)$ and to interventions of a lesser time/intensity with $\left(\mathrm{I}^{2}=66 \%\right)$ and without $\mathrm{OST}\left(\mathrm{I}^{2}=66 \%\right)$, again potentially explained by the differences in intervention content and delivery described above. All HIV testing and counselling intervention control groups received two sessions compared to the intervention conditions that ranged from seven [49] to ten sessions [18] in comparison. 


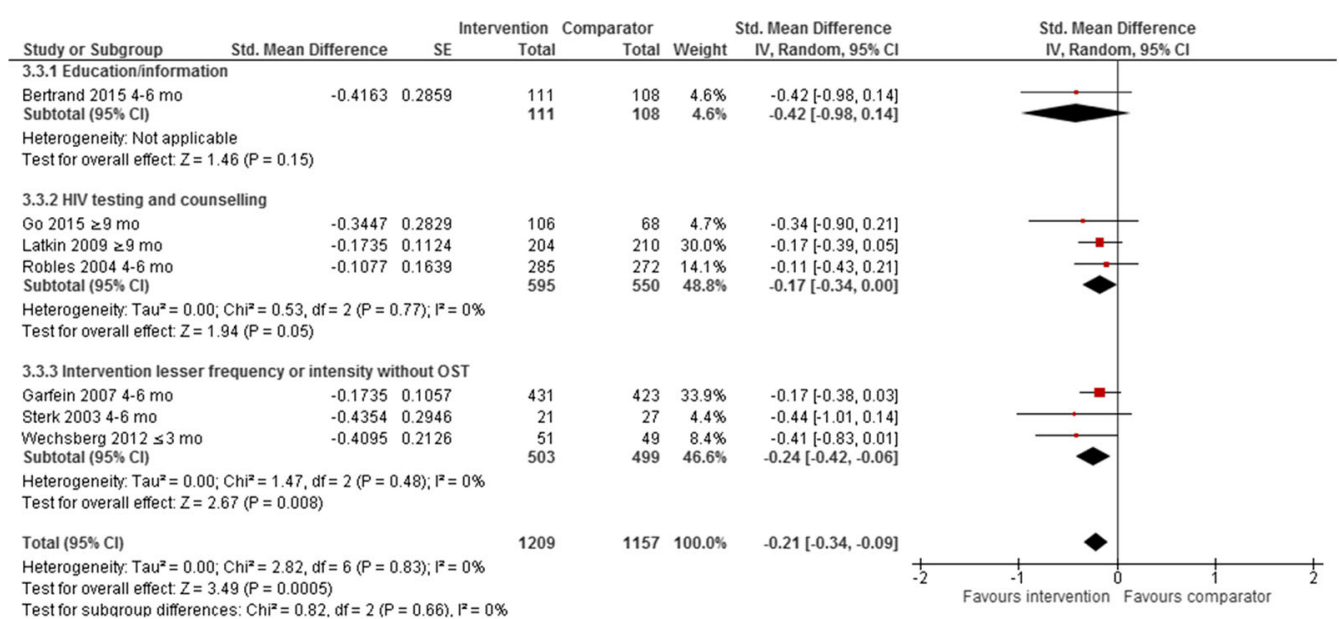

(c)

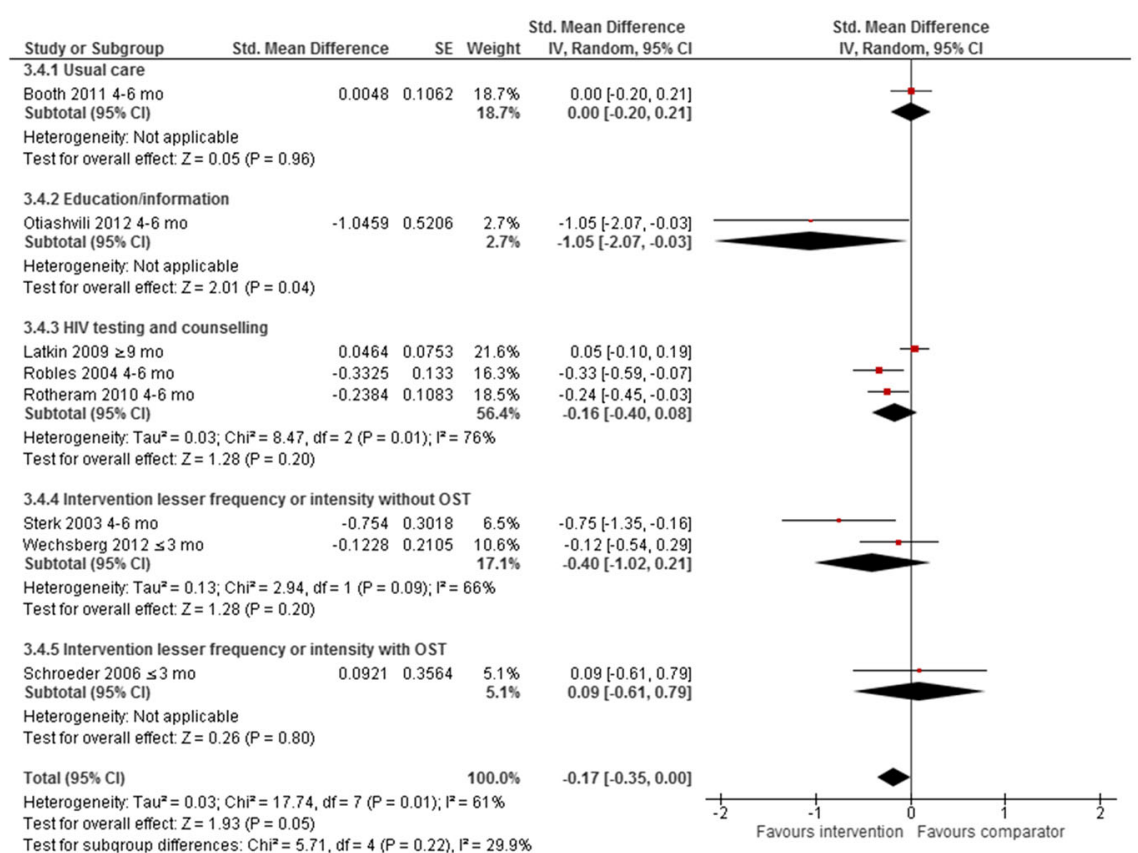

(d)

Fig. 3 continued

\section{Any Sexual Risk Behaviour}

Ten RCTs assessed any sexual risk behaviour (Fig. 4a). Psychosocial interventions were independently more likely to reduce any sexual risk behaviour than the control interventions in two trials [22, 24]. A total of 1359 and 1409 PWID were included in the intervention and control groups respectively. Overall, psychosocial interventions reduced any sexual risk behaviour compared with control interventions (SMD -0.19; 95\% CI $-0.39,0.01$; $\left.\mathrm{I}^{2}=58 \% ; \mathrm{p}=0.07\right)$. Psychosocial interventions showed no difference in reducing any sexual risk behaviours compared with education/information (SMD -0.12; $95 \%$
CI -0.32 to $\left.0.09 ; \mathrm{I}^{2}=34 \% ; \mathrm{p}=0.27\right)$, interventions of a lesser time or intensity with (SMD -0.26 ; 95\% CI -0.67 to $\left.0.15 ; \mathrm{I}^{2}=78 \% ; \mathrm{p}=0.21\right)$; and without OST (SMD $-0.17 ; 95 \%$ CI $-1.41,1.07 ; \mathrm{I}^{2}=72 \%$; $\left.=0.79\right)$; and HIV testing and counselling (SMD 0.14; 95\% CI $-0.81,1.09 ; \mathrm{p}=0.77$; one trial). Where outcomes were compared $\leq 3$ months post-intervention, psychosocial interventions reduced any sexual risk behaviour compared with interventions of a lesser time or intensity (without OST) (Table 3). The high heterogeneity in the analysis comparing psychosocial interventions to interventions of a lesser time or intensity with $\left(\mathrm{I}^{2}=78 \%\right)$ and without OST $\left(\mathrm{I}^{2}=72 \%\right)$ has already been discussed. 


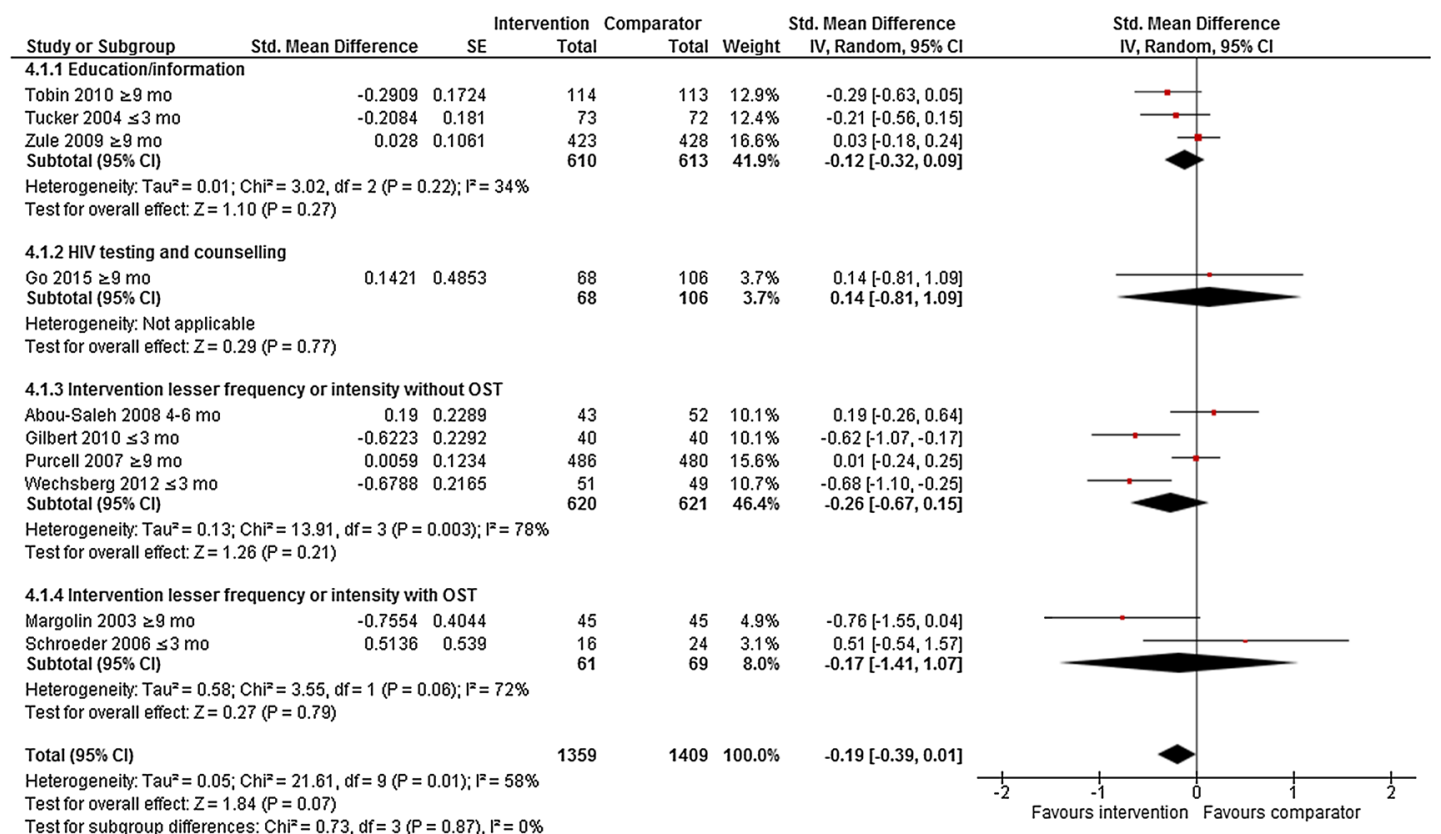

(a)

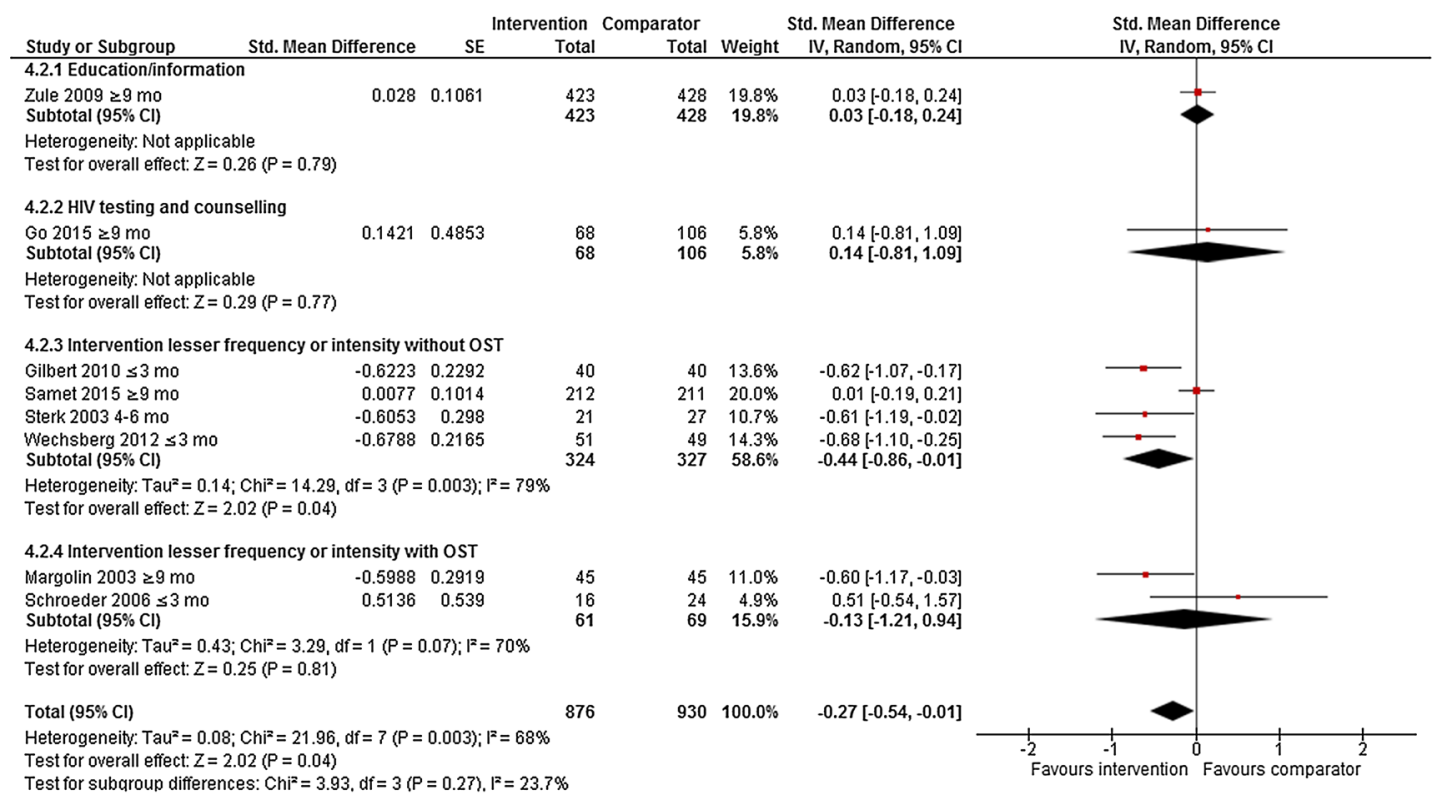

(b)

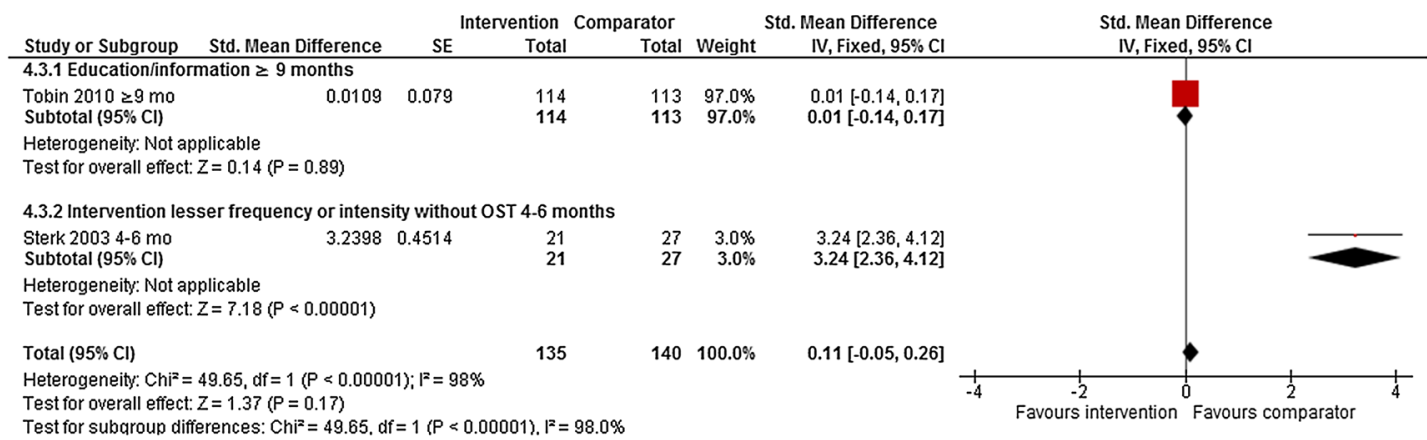

(c) 
4Fig. 4 Efficacy of psychosocial interventions versus control interventions in reducing a ANY sexual risk behaviours among people who inject drugs, $\mathbf{b}$ unprotected sex among people who inject drugs, c number of sexual partners among people who inject drugs

\section{Unprotected Sex}

Eight RCTs assessed unprotected sex (Fig. 4b). Psychosocial interventions were independently more effective than the control interventions in four trials [22, 24, 29, 43]. A total of 876 and 930 PWID were included in the intervention and control groups respectively. Overall, psychosocial interventions reduced unprotected sex more than control interventions (SMD $-0.27 ; 95 \%$ CI -0.54 to $\left.-0.01 ; \mathrm{I}^{2}=68 \% ; \mathrm{p}=0.04\right)$. Psychosocial interventions reduced unprotected sex compared with interventions of a lesser time or intensity (without OST) (SMD $-0.44 ; 95 \%$ CI -0.86 to $\left.-0.01 ; \mathrm{I}^{2}=79 \% ; \mathrm{p}=0.04\right)$; but no difference was reported when compared with education/information (SMD 0.03; 95\% CI -0.18 to 0.24 ; $\mathrm{p}=0.79$; one trial), interventions of a lesser time or intensity with OST (SMD $-0.13 ; 95 \%$ CI -1.21 to $0.94 ; \quad \mathrm{I}^{2}=70 \%$; $\mathrm{p}=0.81$ ); and HIV testing and counselling (SMD 0.14; $95 \% \mathrm{CI}-0.81,1.09 ; \mathrm{p}=0.77$; one trial). Where outcomes were compared $\leq 3$ and 4-6 months post-intervention, psychosocial interventions reduced unprotected sex compared to interventions of a lesser time or intensity (without OST). Where outcomes were assessed $\geq 9$ months postintervention, psychosocial interventions reduced unprotected sex compared with interventions of a lesser time or intensity (with OST) (Table 3).

\section{Number of Sexual Partners}

Two RCTs assessed number of sexual partners (Fig. 4c). A total of 135 and 140 PWID were included in the intervention and control groups respectively. There was no difference between psychosocial interventions and education/information in reducing the number of sexual partners (SMD 0.01 ; $95 \%$ CI -0.14 to 0.17 ; one trial). Interventions of a lesser time or intensity (without OST) reduced the number of sexual partners compared with psychosocial interventions (SMD 3.24; 95\% CI 2.36,4.12; one trial).

\section{Discussion}

The aim of the review and meta-analysis was to identify and evaluate the impact of psychosocial interventions designed to reduce injecting risk and sexual risk behaviours among PWID. A total of 24 trials were included in the meta-analysis. Overall, psychosocial interventions reduced some of the target injecting (sharing of needle and syringes and other injecting paraphernalia) and sexual risk behaviour (unprotected sex) outcomes among PWID when compared with control conditions. More specifically, the meta-analysis found that psychosocial interventions reduced the sharing of needles and syringes compared to education/information or HIV testing and counselling, reduced the sharing of other injecting paraphernalia compared to interventions of a lesser time or intensity, reduced the frequency of injecting compared to one trial of education/information, and reduced unprotected sex compared to interventions of a lesser time or intensity. Although psychosocial interventions targeted injecting risk behaviours rather than a reduction in injecting behaviour per se, one trial reported a significant effect $(p=0.05)$ with regards to reduced frequency of injecting. Psychosocial interventions were no more likely than control interventions to reduce the number of sexual partners. However, only two trials were pooled in this specific meta-analysis, and many participants reported being in a steady relationship. Interestingly, they also reported a reduction in unprotected sex, a factor which may be more important in reducing $\mathrm{BBV}$ transmission than the number of sex partners $[25,29]$.

Using data on outcomes collected at nine-months or more post-intervention, the meta-analyses found psychosocial interventions produced more reported behaviour change than control interventions, suggesting that maintenance or booster sessions may be required to sustain positive behaviour change.

One study found stronger intervention effects for those who had known their HCV-positive status for at least six months, but not for those who had known their HCVpositive status for more than 12 months [41], suggesting a window of opportunity may exist following HCV diagnosis to address transmission risks.

Overall and regardless of intervention or control content, 16 of the 32 trials included in the systematic review reported greater reductions in injecting or sexual risk behaviours in participants in the intervention group compared to the control group [21, 22, 24-26, 29, 32, 35, 37, 38, 41, 43, 45, 46, 48, 49]. Only two trials in the review (with small sample sizes) included contingency management (incentivisation). One of these trials reported greater reductions in injecting risk behaviours in the intervention group (22 sessions of motivational interviewing for the male participant and couple (female partner drug-free) plus contingency management and naltrexone) compared to the control group (22 sessions of education, including referrals to a detoxification programme and aftercare that may or may not have included naltrexone) [46]. The other reported no significant difference in injecting or sexual risk behaviours between the intervention (29 week intervention including 12 weeks 
of CBT and contingent vouchers (as well as standard care: methadone +5 weekly individual counselling, followed by 12 weeks standard treatment) and control groups (29 week standard care intervention (same as intervention group) including 12 weeks of group therapy and noncontingent vouchers) [20] (Table 1). Only three of the seven trials [18, 19, 26, 33, 37, 43, 53] of psychosocial interventions including motivational interviewing found greater reductions in some injecting and sexual risk behaviours [26, 37, 43]. As these three interventions varied in content and participant group (e.g. one session interactive session for female sex workers [26]; computerised intervention (69\% male) [37]; and PWID entering OST (70\% male) [43]; results about the effectiveness of specific intervention functions (e.g. incentivisation or persuasion) in reducing $\mathrm{BBV}$ risk behaviours among PWID are inconclusive.

\section{Limitations}

Limitations include the low number of studies for inclusion in some of the sub-group analyses of behavioural outcomes and intervention delivery modes. In addition, there was heterogeneity in terms of the interventions studied and their duration, as well as differences in sample sizes and characteristics, length of follow-up, and assessment methods used to determine risk behaviours. This lack of consistency across studies may have contributed to the moderate levels of heterogeneity noted in the meta-analyses. The most common risk of bias in included RCTs was selective outcome reporting and possible cross-over contamination between groups. A further limitation is that authors of the eight trials not included in the meta-analysis were not contacted to determine whether they could supply the additional data required to include the trial in the metaanalysis. It is acknowledged that this could have resulted in a potential source of bias in the findings. These limitations need to be considered when interpreting the results.

\section{Conclusions}

Whilst indications from the meta-analysis suggest that psychosocial interventions (when compared to control) reduce risk taking behaviour outcomes, more research is needed. The findings highlight the difficulty and complexity involved in attempting to examine the effectiveness of interventions that include different content and functions, modes of delivery, dosage and number of sessions. This heterogeneity in both the control and intervention conditions resulted in challenges to fully interpret the findings. It will be important to determine what types of psychosocial interventions work for whom and in what settings [8]. Our findings suggest that psychosocial interventions could boost the impact of current harm reduction interventions delivered as routine care and could be included with other harm reduction approaches, including OST and needle and syringe exchange, to reduce BBV transmission risks among PWID. Further trials should address some of the limitations in terms of target populations, dose and frequency and timing of outcome measures.

Acknowledgements This manuscript presents independent research funded by the National Institute for Health Research (NIHR) under the Health Technology Assessment programme [project number 13/17/04]. The findings from this review will also be published as part of the full project report "Preventing blood borne virus infection in people who inject drugs in the UK: the development and feasibility of psychosocial interventions" in Health Technology Assessment. The views expressed in this publication are those of the authors and not necessarily those of the NHS, the NIHR or the Department of Health. We are grateful to Dr Benjamin Gardner from King's College London for his assistance with determining intervention functions on a sub sample of trials included in this review.

\section{Compliance with Ethical Standards}

Conflict of interest The authors declare that they have no conflict of interest.

Ethical Approval For this type of study formal consent is not required.

Informed Consent For this type of study informed consent is not required.

Open Access This article is distributed under the terms of the Creative Commons Attribution 4.0 International License (http://crea tivecommons.org/licenses/by/4.0/), which permits unrestricted use, distribution, and reproduction in any medium, provided you give appropriate credit to the original author(s) and the source, provide a link to the Creative Commons license, and indicate if changes were made.

\section{References}

1. Hahné SJ, Veldhuijzen IK, Wiessing L, Lim TA, Salminem M, Laar MV. Infection with hepatitis B and C virus in Europe: a systematic review of prevalence and cost-effectiveness of screening. BMC Infect Dis. 2013;13:181.

2. Mathers BM, Degenhardt L, Phillips B, et al. Global epidemiology of injecting drug use and HIV among people who inject drugs: a systematic review. Lancet. 2008;372(9651):1733-45.

3. Baeten J, Celum C. Systemic and topical drugs for the prevention of HIV infection: antiretroviral pre-exposure prophylaxis. Annu Rev Med. 2013;64:219-32.

4. Aspinall EJ, Corson S, Doyle JS, et al. Treatment of hepatitis C virus infection among people who are actively injecting drugs: a systematic review and meta-analysis. Clin Infect Dis. 2013;57(Suppl 2):S80-9.

5. MacArthur GJ, van Velez E, Palmateer N, et al. Interventions to prevent HIV and Hepatitis $\mathrm{C}$ in people who inject drugs: a review of reviews to assess evidence of effectiveness. Int J Drug Policy. 2014;25(1):34-52. 
6. Hagan H, Pouget ER, Des Jarlais DC. A systematic review and metaanalysis of interventions to prevent hepatitis $\mathrm{C}$ virus infection in people who inject drugs. J Infect Dis. 2011;204(1):74-83.

7. Meader N, Li R, Des Jarlais DC, Pilling S. Psychosocial interventions for reducing injection and sexual risk behaviour for preventing HIV in drug users. Cochrane Database Syst Rev. 2010;1:CD007192.

8. Meader N, Semaan S, Halton M, et al. An international systematic review and meta-analysis of multisession psychosocial interventions compared with educational or minimal interventions on the HIV sex risk behaviors of people who use drugs. AIDS Behav. 2013;17(6):1963-78.

9. Sacks-Davis R, Horyniak D, Grebely J, Hellard M. Behavioural interventions for preventing hepatitis $\mathrm{C}$ infection in people who inject drugs: a global systematic review. Int $\mathrm{J}$ Drug Policy. 2012;23(3):176-84.

10. Michie S, van Stralen MM, West R. The behaviour change wheel: a new method for characterising and designing behaviour change interventions. Implement Sci. 2011;6:42.

11. Harrell PT, Mancha BE, Petras H, Trenz RC, Latimer WW. Latent classes of heroin and cocaine users predict unique HIV/ HCV risk factors. Drug Alcohol Depend. 2012;122(3):220-7.

12. Booth RE, Strathdee SA. Baseline findings from the third collaborative injection drug users study/drug users intervention trial (CIDUS III/DUIT). Drug Alcohol Depend. 2007;91(Suppl 1):S1-3.

13. Gilchrist G, Singleton N, Donmall M, Jones A. Prevalence and factors associated with sex trading in the year prior to entering treatment for drug misuse in England. Drug Alcohol Depend. 2015;152:116-22.

14. Jin H, Huriaux E, Loughran E, Packer T, Raymond HF. Differences in HIV risk behaviors among people who inject drugs by gender and sexual orientation, San Francisco, 2012. Drug Alcohol Depend. 2014;145:180-4.

15. Moher D, Liberati A, Tetzlaff J, Altman DG. PRISMA Group. Preferred reporting items for systematic reviews and meta-analyses: the PRISMA statement. J Clin Epidemiol. 2009;62(10):1006-12.

16. Higgins JP, Altman DG, Gøtzsche PC, et al. The Cochrane Collaboration's tool for assessing risk of bias in randomised trials. BMJ. 2011;343:d5928.

17. Booth RE, Campbell BK, Mikulich-Gibertson SK, et al. Reducing HIV-related risk behaviors among injection drug users in residential detoxification. AIDS Behav. 2011;15(1):30-44.

18. Latkin CA, Donell D, Metzger D, et al. The efficacy of a network intervention to reduce HIV risk behaviors among drug users and risk partners in Chiang Mai, Thailand and Philadelphia, USA. Soc Sci Med. 2009;68(4):740-8.

19. Zule WA, Costenbader EC, Curtis CM, Wechsberg WM. Effects of a hepatitis $\mathrm{C}$ virus educational intervention or a motivational intervention on alcohol use, injection drug dse, and sexual risk behaviours among injection drug users. Am J Public Health. 2009;99(Suppl 1):S180-6.

20. Schroeder JR, Epstein DH, Umbricht A, Preston KL. Changes in HIV risk behaviors among patients receiving combined pharmacological and behavioral interventions for heroin and cocaine dependence. Addict Behav. 2006;31(5):868-79.

21. Latkin CA, Sherman S, Knowlton A. HIV prevention among drug users: outcome of a network-oriented peer outreach intervention. Health Psychol. 2003;22(4):332-9.

22. Gilbert L, El-Bassel N, Terlikbayeva A, et al. Couple-based HIV prevention for injecting drug users in Kazakhstan: a pilot intervention study. J Prev Interv Community. 2010;38(2):162-76.

23. Hoffman IF, Latkin CA, Kukhareva PV, et al. A peer-educator network HIV prevention intervention among injection drug users: results of a randomized controlled trial in St. Petersburg, Russia. AIDS Behav. 2013;17(7):2510-20.

24. Wechsberg WM, Krupitsky E, Romanova T, et al. Double jeopardy-drug and sex risks among Russian women who inject drugs: initial feasibility and efficacy results of a small randomized controlled trial. Subst Abuse Treat Prev Policy. 2012;7:1.

25. Tobin KE, Kuramoto SJ, Davey-Rothwell MA, Latkin CA. The STEP into Action study: a peer-based, personal risk networkfocused HIV prevention intervention with injection drug users in Baltimore, Maryland. Addiction. 2011;106(2):366-75.

26. Strathdee SA, Abramovitz D, Lozada R, et al. Reductions in HIV/ STI incidence and sharing of injection equipment among female sex workers who inject drugs: results from a randomized controlled trial. PLoS ONE. 2013;8(6):e65812.

27. Bland JM, Altman DG. Statistics notes. The odds ratio. BMJ.2000;320:1468.

28. Higgins JP, Thompson SG, Deeks JJ, Altman DG. Measuring inconsistency in meta-analyses. BMJ. 2003;327(7414):557-60.

29. Sterk CE, Theall KP, Elifson KW, Kidder D. HIV risk reduction among African-American women who inject drugs: a randomized controlled trial. AIDS Behav. 2003;7(1):73-86.

30. Go VF, Frangakis C, Minh NL, et al. Efficacy of a multi-level intervention to reduce injecting and sexual risk behaviors among HIV-infected people who inject drugs in Vietnam: a four-arm randomized controlled trial. PLoS ONE. 2015;10(5):e0125909.

31. Abou-Saleh M, Davis P, Rice P, et al. The effectiveness of behavioural interventions in the primary prevention of hepatitis $\mathrm{C}$ amongst injecting drug users: a randomised controlled trial and lessons learned. Harm Reduct J. 2008;5:25.

32. Avants SK, Margolin A, Usubiaga MH, Doebrick C. Targeting HIV-related outcomes with intravenous drug users maintained on methadone: a randomized clinical trial of a harm reduction group therapy. J Subst Abuse Treat. 2004;26(2):67-78.

33. Bertrand K, Roy É, Vaillancourt É, Vandermeerschen J, Berbiche D, Boivin JF. Randomized controlled trial of motivational interviewing for reducing injection risk behaviours among people who inject drugs. Addiction. 2015;110(5):832-41.

34. Dushay RA, Singer M, Weeks MR, Rohena L, Gruber R. Lowering HIV risk among ethnic minority drug users: comparing culturally targeted intervention to a standard intervention. Am J Drug Alcohol Abuse. 2001;27(3):501-24.

35. El-Bassel N, Gilber L, Wu E, et al. Couple-based HIV Prevention for low-income drug users from New York City: a randomized controlled trial to reduce dual risks. J Acquir Immune Defic Syndr. 2011;58(2):198-206.

36. Epstein DH, Hawkins WE, Covi L, Umbricht A, Preston KL. Cognitive-behavioral therapy plus contingency management for cocaine use: findings during treatment and across 12-month follow-up. Psychol Addict Behav. 2003;17(1):73-82.

37. Gagnon H, Godin G, Alary M, Bruneau J, Otis J. A randomized trial to evaluate the efficacy of a computer-tailored intervention to promote safer injection practices among drug users. AIDS Behav. 2010;14(3):538-48.

38. Garfein RS, Golub ET, Greenberg AE, et al. A peer-education intervention to reduce injection risk behaviors for HIV and hepatitis $\mathrm{C}$ virus infection in young injection drug users. AIDS. 2007;21(14):1923-32.

39. Go VF, Frangakis C, Le Minh N, et al. Effects of an HIV peer prevention intervention on sexual and injecting risk behaviors among injecting drug users and their risk partners in Thai Nguyen, Vietnam: a randomized controlled trial. Soc Sci Med. 2013;96:154-64.

40. Hershberger SL, Wood MM, Fisher DG. A cognitive-behavioral intervention to reduce HIV risk behaviors in crack and injection drug users. AIDS Behav. 2003;7(3):229-43. 
41. Latka MH, Hagan H, Kapadia F, et al. A randomized intervention trial to reduce the lending of used injection equipment among injection drug users infected with hepatitis C. Am J Public Health. 2008;98(5):853-61.

42. Mackesy-Amiti ME, Oullet LJ, Golub ET, Hudson S, Hagan H, Garfein RS. Predictors and correlates of reduced frequency or cessation of injection drug use during a randomized HIV prevention intervention trial. Addiction. 2011;106(3):601-8.

43. Margolin A, Avants SK, Warburton LA, Hawkins KA, Shi J. A randomized clinical trial of a manual-guided risk reduction intervention for HIV-positive injection drug users. Health Psychol. 2003;22(2):223-8.

44. McMahon JM, Pouget ER, Tortu S, Volpe EM, Torres L, Rodriguez W. Couple-based HIV counseling and testing: a risk reduction intervention for US drug-involved women and their primary male partners. Prev Sci. 2015;16(2):341-51.

45. McMahon JM, Tortu S, Pouget ER, Torres L, Rodriguz W, Hamid R. Effectiveness of couple-based HIV counseling and testing for women substance users and their primary male partners: a randomized trial. Adv Prev Med. 2013;2013:286207.

46. Otiashvili D, Kirtadze I. ÓGrady KE, Jones HE. Drug use and HIV risk outcomes in opioid-injecting men in the Republic of Georgia: behavioral treatment + naltrexone compared to usual care. Drug Alcohol Depend. 2012;120(1-3):14-21.

47. Purcell DW, Latka MH, Metsch LR, et al. Results from a randomized controlled trial of a peer-mentoring intervention to reduce HIV transmission and increase access to care and adherence to HIV medications among HIV-seropositive injection drug users. J Acquir Immune Defic Syndr. 2007;46(Suppl 2):S35-47.

48. Robles RR, Reyes JC, Colón HM, et al. Effects of combined counseling and case management to reduce HIV risk behaviors among Hispanic drug injectors in Puerto Rico: a randomized controlled study. J Subst Abuse Treat. 2004;27(2):145-52.

49. Rotheram-Borus MJ, Rhodes F, Desmond K, Weiss RE. Reducing HIV risks among active injection drug and crack users: the safety counts program. AIDS Behav. 2010;14(3):658-68.

50. Samet JH, Raj A, Cheng DM, et al. HERMITAGE-a randomized controlled trial to reduce sexually transmitted infections and HIV risk behaviors among HIV-infected Russian drinkers. Addiction. 2015;110(1):80-90.

51. Stein MD, Anderson B, Charuvastra A, Maksad J, Friedmann PD. A brief intervention for hazardous drinkers in a needle exchange program. J Subst Abuse Treat. 2002;22(1):23-31.
52. Stein MD, Anderson BJ, Solomon DA, et al. Reductions in HIV risk behaviors among depressed drug injectors. Am J Drug Alcohol Abuse. 2005;31(3):417-32.

53. Stein MD, Herman DS, Anderson BJ. A trial to reduce hepatitis C seroincidence in drug users. J Addict Dis. 2009;28(4):389-98.

54. Tucker T, Fry CL, Lintzeris N, et al. Randomized controlled trial of a brief behavioural intervention for reducing hepatitis $\mathrm{C}$ virus risk practices among injecting drug users. Addiction. 2004;99(9):1157-66.

55. Vera A, Abramovitz D, Lozada R, et al. Mujer Mas Segura (Safer Women): a combination prevention intervention to reduce sexual and injection risks among female sex workers who inject drugs. BMC Public Health. 2012;12:653.

56. Purcell DW, Metsch LR, Latka M, et al. Interventions for seropositive injectors-research and evaluation: an integrated behavioral intervention with HIV-positive injection drug users to address medical care, adherence, and risk reduction. J Acquir Immune Defic Syndr. 2004;37(Suppl 2):S110-8.

57. Latkin C, Donnell D, Liu T-Y, Davey-Rothwell M, Celentano D, Metzger D. The dynamic relationship between social norms and behaviors: the results of an HIV prevention network intervention for injection drug users. Addiction. 2013;108(5):934-43.

58. Kapadia F, Latka MH, Hagan H, et al. Design and feasibility of a randomized behavioral intervention to reduce distributive injection risk and improve health-care access among hepatitis $\mathrm{C}$ virus positive injection drug users: the Study to Reduce Intravenous Exposures (STRIVE). J Urban Health. 2007;81:99-115.

59. Go VF, Frangakis C, Le Minh N, et al. Effects of an HIV peer prevention intervention on sexual and injecting risk behaviors among injecting drug users and their risk partners in Thai Nguyen, Vietnam: a randomized controlled trial. Soc Sci Med. 2013;96:154-64.

60. Mackesy-Amiti ME, Finnegan L, Ouellet LJ, et al. Peer-education intervention to reduce injection risk behaviors benefits highrisk young injection drug users: a latent transition analysis of the CIDUS 3/DUIT study. AIDS Behav. 2013;17:2075-83.

61. Mackesy-Amiti ME, Ouellet LJ, Finnegan L, et al. Transitions in latent classes of sexual risk behavior among young injection drug users following HIV prevention intervention. AIDS Behav. 2014;18:464-72. 